\title{
Common breast cancer susceptibility alleles are associated with tumour subtypes in BRCA1 and $B R C A 2$ mutation carriers: results from the Consortium of Investigators of Modifiers of BRCA1/2
}

Anna Marie Mulligan', Fergus J Couch², Daniel Barrowdale ${ }^{3}$, Susan M Domchek ${ }^{4}$, Diana Eccles ${ }^{5}$, Heli Nevanlinna ${ }^{6}$, Susan J Ramus ${ }^{7}$, Mark Robson ${ }^{8}$, Mark Sherman ${ }^{9}$, Amanda B Spurdle ${ }^{10}$, Barbara Wappenschmidt ${ }^{11}$, Andrew Lee ${ }^{3}$, Lesley McGuffog ${ }^{3}$, Sue Healey ${ }^{10}$, Olga M Sinilnikova ${ }^{12,13}$, Ramunas Janavicius ${ }^{14}$, Thomas $v O$ Hansen ${ }^{15}$, Finn C Nielsen ${ }^{15}$, Bent Ejlertsen ${ }^{16}$, Ana Osorio ${ }^{17}$, Iván Muñoz-Repeto ${ }^{17}$, Mercedes Durán ${ }^{18}$, Javier Godino ${ }^{19}$, Maroulio Pertesi ${ }^{20}$, Javier Benítez ${ }^{21}$, Paolo Peterlongo ${ }^{22}$, Siranoush Manoukian ${ }^{23}$, Bernard Peissel ${ }^{23}$, Daniela Zaffaroni ${ }^{23}$, Elisa Cattaneo ${ }^{23}$, Bernardo Bonanni ${ }^{24}$, Alessandra Viel ${ }^{25}$, Barbara Pasini ${ }^{26}$, Laura Papi ${ }^{27}$, Laura Ottini ${ }^{28}$, Antonella Savarese ${ }^{29}$, Loris Bernard ${ }^{30}$, Paolo Radice ${ }^{22}$, Ute Hamann ${ }^{31}$, Martijn Verheus ${ }^{32}$, Hanne EJ Meijers-Heijboer ${ }^{33}$, Juul Wijnen ${ }^{34}$, Encarna B Gómez García ${ }^{35}$, Marcel R Nelen ${ }^{36}$, C Marleen Kets ${ }^{37}$, Caroline Seynaeve ${ }^{38}$, Madeleine MA Tilanus-Linthorst ${ }^{39}$, Rob B van der Luijt ${ }^{40}$, Theo van Os ${ }^{41}$, Matti Rookus ${ }^{32}$, Debra Frost ${ }^{3}$, J Louise Jones ${ }^{42}$, D Gareth Evans ${ }^{43}$, Fiona Lalloo ${ }^{43}$, Ros Eeles ${ }^{44}$, Louise Izatt ${ }^{45}$, Julian Adlard ${ }^{46}$, Rosemarie Davidson ${ }^{47}$, Jackie Cook $^{48}$, Alan Donaldson ${ }^{49}$, Huw Dorkins ${ }^{50}$, Helen Gregory ${ }^{51}$, Jacqueline Eason ${ }^{52}$, Catherine Houghton ${ }^{53}$, Julian Barwell ${ }^{54}$, Lucy E Side ${ }^{55}$, Emma McCann ${ }^{56}$, Alex Murray ${ }^{57}$, Susan Peock ${ }^{3}$, Andrew K Godwin ${ }^{58}$, Rita K Schmutzler ${ }^{11}$, Kerstin Rhiem ${ }^{11}$, Christoph Engel ${ }^{59}$, Alfons Meindl ${ }^{60}$, Ina Ruehl ${ }^{61}$, Norbert Arnold ${ }^{62}$, Dieter Niederacher ${ }^{63}$, Christian Sutter ${ }^{64}$, Helmut Deissler $^{65}$, Dorothea Gadzicki ${ }^{66}$, Karin Kast ${ }^{67}$, Sabine Preisler-Adams ${ }^{68}$, Raymonda Varon-Mateeva ${ }^{69}$, Ines Schoenbuchner ${ }^{70}$, Britta Fiebig ${ }^{71}$, Wolfram Heinritz ${ }^{72}$, Dieter Schäfer ${ }^{73}$, Heidrun Gevensleben ${ }^{74}$, Virginie Caux-Moncoutier ${ }^{75}$, Marion Fassy-Colcombet ${ }^{75}$, François Cornelis ${ }^{76}$, Sylvie Mazoyer ${ }^{13}$, Mélanie Léoné ${ }^{12}$, Nadia Boutry-Kryza ${ }^{12}$, Agnès Hardouin ${ }^{77}$, Pascaline Berthet ${ }^{77}$, Danièle Muller ${ }^{78}$, Jean-Pierre Fricker ${ }^{78}$, Isabelle Mortemousque ${ }^{79}$, Pascal Pujol ${ }^{80}$, Isabelle Coupier ${ }^{80}$, Marine Lebrun ${ }^{81}$, Caroline Kientz ${ }^{81}$, Michel Longy ${ }^{82}$, Nicolas Sevenet ${ }^{82}$, Dominique Stoppa-Lyonnet ${ }^{75,83}$, Claudine Isaacs ${ }^{84}$, Trinidad Caldes ${ }^{85}$, Miguel de la Hoya ${ }^{85}$, Tuomas Heikkinen ${ }^{6}$, Kristiina Aittomäki $^{86}$, Ignacio Blanco ${ }^{87}$, Conxi Lazaro ${ }^{87}$, Rosa B Barkardottir ${ }^{88}$, Penny Soucy ${ }^{89}$, Martine Dumont ${ }^{89}$, Jacques Simard ${ }^{90}$, Marco Montagna ${ }^{91}$, Silvia Tognazzo ${ }^{91}$, Emma D’Andrea ${ }^{92}$, Stephen Fox ${ }^{93}$, Max Yan ${ }^{94}$, Tim Rebbeck ${ }^{95}$, Olufunmilayo I Olopade ${ }^{96}$, Jeffrey N Weitzel ${ }^{97}$, Henry T Lynch $^{98}$, Patricia A Ganz ${ }^{99}$, Gail E Tomlinson ${ }^{100}$, Xianshu Wang ${ }^{2}$, Zachary Fredericksen ${ }^{101}$, Vernon S Pankratz ${ }^{101}$, Noralane M Lindor ${ }^{102}$, Csilla Szabo ${ }^{103}$, Kenneth Offit ${ }^{8}$, Rita Sakr ${ }^{8}$, Mia Gaudet ${ }^{104}$, Jasmine Bhatia ${ }^{8}$, Noah Kauff ${ }^{8}$, Christian F Singer $^{105}$, Muy-Kheng Tea ${ }^{105}$, Daphne Gschwantler-Kaulich ${ }^{105}$, Anneliese Fink-Retter ${ }^{105}$, Phuong L Mai ${ }^{106}$, Mark H Greene ${ }^{106}$, Evgeny Imyanitov ${ }^{107}$, Frances P O'Malley ${ }^{108}$, Hilmi Ozcelik ${ }^{109}$, Gordon Glendon ${ }^{110}$, Amanda E Toland ${ }^{111}$, Anne-Marie Gerdes ${ }^{112}$, Mads Thomassen ${ }^{113}$, Torben A Kruse ${ }^{113}$, Uffe Birk Jensen ${ }^{114}$, Anne-Bine Skytte ${ }^{115}$ Maria A Caligo ${ }^{116}$, Maria Soller ${ }^{117}$, Karin Henriksson ${ }^{118}$, von Anna Wachenfeldt ${ }^{119}$, Brita Arver ${ }^{119}$, Marie Stenmark-Askmalm ${ }^{120}$, Per Karlsson ${ }^{121}$, Yuan Chun Ding ${ }^{122}$, Susan L Neuhausen ${ }^{122}$, Mary Beattie ${ }^{123}$, Paul DP Pharoah ${ }^{124}$, Kirsten B Moysich ${ }^{125}$, Katherine L Nathanson ${ }^{4}$, Beth Y Karlan ${ }^{126}$, Jenny Gross ${ }^{126}$, 
Esther M John ${ }^{127}$, Mary B Daly ${ }^{128}$, Saundra M Buys ${ }^{129}$, Melissa C Southey ${ }^{130}$, John L Hopper ${ }^{131}$, Mary Beth Terry ${ }^{132}$, Wendy Chung ${ }^{132}$, Alexander F Miron ${ }^{133}$, David Goldgar ${ }^{134}$, Georgia Chenevix-Trench ${ }^{10}$, Douglas F Easton ${ }^{3}$, Irene $L$ Andrulis ${ }^{135}$ and Antonis $C$ Antoniou $^{3^{*}}$ and for Breast Cancer Family Registry ${ }^{136}$ and for EMBRACE ${ }^{3}$ and for GEMO Study Collaborators ${ }^{137}$ and for HEBON ${ }^{138}$ and for kConFab Investigators ${ }^{93}$ and for

Ontario Cancer Genetics Network ${ }^{139}$ and for SWE-BRCA ${ }^{140}$, for CIMBA

\begin{abstract}
Introduction: Previous studies have demonstrated that common breast cancer susceptibility alleles are differentially associated with breast cancer risk for BRCA1 and/or BRCA2 mutation carriers. It is currently unknown how these alleles are associated with different breast cancer subtypes in BRCA1 and BRCA2 mutation carriers defined by estrogen (ER) or progesterone receptor (PR) status of the tumour.

Methods: We used genotype data on up to 11,421 BRCA1 and 7,080 BRCA2 carriers, of whom 4,310 had been affected with breast cancer and had information on either ER or PR status of the tumour, to assess the associations of 12 loci with breast cancer tumour characteristics. Associations were evaluated using a retrospective cohort approach.

Results: The results suggested stronger associations with ER-positive breast cancer than ER-negative for 11 loci in both BRCA1 and BRCA2 carriers. Among BRCA1 carriers, single nucleotide polymorphism (SNP) rs2981582 (FGFR2) exhibited the biggest difference based on ER status (per-allele hazard ratio (HR) for ER-positive $=1.35,95 \%$ Cl: 1.17 to 1.56 vs HR $=0.91,95 \% \mathrm{Cl}: 0.85$ to 0.98 for ER-negative, -heterogeneity $=6.5 \times 10^{-6}$ ). In contrast, SNP rs2046210 at $6 \mathrm{q} 25.1$ near ESR1 was primarily associated with ER-negative breast cancer risk for both BRCA1 and BRCA2 carriers. In BRCA2 carriers, SNPs in FGFR2, TOX3, LSP1, SLC4A7/NEK10, 5p12, 2q35, and 1p11.2 were significantly associated with ER-positive but not ER-negative disease. Similar results were observed when differentiating breast cancer cases by PR status.

Conclusions: The associations of the 12 SNPs with risk for BRCA1 and BRCA2 carriers differ by ER-positive or ERnegative breast cancer status. The apparent differences in SNP associations between BRCA1 and BRCA2 carriers, and non-carriers, may be explicable by differences in the prevalence of tumour subtypes. As more risk modifying variants are identified, incorporating these associations into breast cancer subtype-specific risk models may improve clinical management for mutation carriers.
\end{abstract}

\section{Introduction}

Germline mutations in BRCA1 and BRCA2 confer high risks of breast, ovarian and other cancers [1-3] and account for 15 to $20 \%$ of the excess familial risk of breast cancer among first degree relatives [4,5]. Breast cancer risks for $B R C A 1$ and $B R C A 2$ mutation carriers have been estimated to range between 40 and $87 \%$ by age 70 [6-12] with population-based estimates tending to be lower than estimates based on families with multiple affected individuals [6,8]. Moreover, breast cancer risks for mutation carriers were found to vary according to the age at diagnosis and the type of cancer of the index patient involved in the family ascertainment $[6,7,11]$. Such evidence suggests that genetic or other risk factors that cluster in families modify the cancer risks conferred by $B R C A 1$ and $B R C A 2$ mutations.

A substantial body of work indicates that tumours arising in patients with germline $B R C A 1$ mutations are morphologically and genetically distinct from those arising in carriers of BRCA2 mutations and from tumours in patients lacking mutations. In gene expression studies, BRCA1-associated tumours are often classified as basal subtype tumours $[13,14]$. This is reflected in their higher grade, and morphologic features including lymphocytic infiltrate, pushing margins and syncytial growth. Being basal-like they express several markers that are normally expressed in the basal/myoepithelial cells of the breast, including stratified epithelial cytokeratins 5/6,14 and 17. BRCA1-associated tumours are more likely to be estrogen receptor (ER), progesterone receptor (PR) and HER2 negative and to harbor mutations in the TP53 gene than age-matched sporadic breast cancers $[15,16]$. BRCA2-associated tumours are also predominantly high-grade invasive ductal carcinomas of no special type but they often demonstrate a luminal phenotype despite their high histologic grade $[13,17]$. Adjusting for grade, $B R C A 2$-associated tumours are more often ER-positive and are less likely, compared with controls, to express the basal cytokeratin CK5 or to overexpress HER2/neu protein [17]. 
Establishing the estrogen receptor status of a breast cancer (positive or negative) reflects a major subdivision in breast cancer type (at least five major sub-types are recognized) and it is becoming clear that the risk factors associated with breast cancer, both genetic and epidemiological, differ according to sub-type. Genome-wide association studies (GWAS) in breast cancer have identified several common alleles (single nucleotide polymorphisms (SNPs)) associated with an increased risk of breast cancer in the general population [18-25]. Many of these SNPs are associated with risk for ER-positive breast cancer, fewer have so far been associated with ER-negative breast cancer risk [26,27].

Known risk breast cancer susceptibility alleles have been genotyped in a large series of female $B R C A 1$ and $B R C A 2$ mutation carriers assembled by the Consortium of Investigators of Modifiers of BRCA1/2 (CIMBA) to evaluate their associations with risk of breast cancer for mutation carriers. Of the 12 SNPs (rs2981582 in FGFR2, rs3803662 in TOX3/TNRC9, rs889312 in MAP3K1, rs13281615 at $8 \mathrm{q} 24, \mathrm{rs} 381798$ in $L S P 1, \mathrm{rs} 13387042$ at 2q35, rs4973768 in SLC4A7/NEK10, rs10941679 at 5p12, rs6504950 in STXBP4/COX11, rs999737/rs10483813 in $R A D 51 L 1$, rs2046210 at $6 \mathrm{q} 25.1$ and rs11249433 at $1 \mathrm{p} 11.2)$ investigated so far, eight were associated with breast cancer risk for $B R C A 2$ carriers (all but SNPs at 8q24, RAD51L1, 6q25.1 and STXBP4/COX11), whereas only three SNPs (6q25.1, TOX3/TNRC9 and 2q35) were associated with risk for BRCA1 mutation carriers [28-31]. Work from the Breast Cancer Association Consortium and subsequent studies have demonstrated differences in the associations between these susceptibility loci and tumour characteristics in the general population [27,32]. These results suggest that the observed differences in the associations between $B R C A 1$ and $B R C A 2$ mutation carriers may reflect differences in the distribution of tumour characteristics in mutation carriers. It is currently unclear whether these polymorphisms are associated with different tumour characteristics within $B R C A 1$ and $B R C A 2$ mutation carriers.

As an adjunct to predictive testing for a high risk $B R C A 1$ or BRCA2 gene mutation, more individualized risk estimates that take into account additional genetic and environmental modifiers will require a more detailed understanding of how these various risk factors interact. Understanding whether common genetic variants modify the risks of developing ER-positive or ERnegative breast cancer in BRCA1 and BRCA2 mutation carriers could potentially influence the clinical management of these individuals. For example, knowing that a $B R C A 1$ mutation carrier is more likely to develop ERpositive breast cancer (than most BRCA1 mutation carriers), may influence the choice of management strategies, such as chemoprevention. In this study, we used data from the CIMBA consortium to evaluate the associations between the 12 common breast cancer susceptibility alleles and risk for breast cancer defined by ER and PR status.

\section{Materials and methods Subjects}

Subjects were BRCA1 and BRCA2 mutation carriers recruited by 36 study centres in Europe, North America and Australia (Table 1). All carriers participated in clinical or research studies at the host institutions, which have been approved by local ethics committees (list provided in Additional file 1, Table S1). Each committee granted approval for access and use of the medical records for the present analyses.

The large majority of carriers were recruited through cancer genetics clinics offering genetic testing, and enrolled into national or regional studies. Eligibility to participate in CIMBA is restricted to female carriers of pathogenic $B R C A 1$ or $B R C A 2$ mutations who were 18 years old or older at recruitment. Information collected included the year of birth; mutation description, including nucleotide position and base change; age at last follow-up; ages at breast and ovarian cancer diagnoses; and age or date at bilateral prophylactic mastectomy. Information was also available on the country of residence. Related individuals were identified through a unique family identifier. Women were included in the analysis if they carried mutations that were pathogenic according to generally recognized criteria. Only studies that provided tumour pathology information and had genotype information were included in the analysis. However, to maximise the available information, genotyped mutation carriers within those studies missing information on tumour characteristics were included in the analysis and their disease subtype was assumed to be missing at random (see statistical methods for details). Further details about the CIMBA initiative can be found elsewhere [33].

\section{Tumour pathology data collection}

Tumour pathology data were amalgamated from a range of sources, specifically patient pathology reports, medical records, pathology review data, tumour registry records and results from tissue microarrays. Estrogen and progesterone receptor status was provided as negative or positive, with supplementary immunohistochemistry scoring data and methodology provided when available. Based on definitions supplied, most centres employed a cut off of $\geq 10 \%$ of tumour cells stained positive to define receptor positivity. To ensure consistency across studies, when information on the proportion of cells stained was available, we used the same cut-off to define ER and PR positive tumours. For a small number of cases where composite scoring methods based on the 
Table 1 Number of mutation carriers by country grouping affection status and tumour marker characteristics

\begin{tabular}{|c|c|c|c|c|c|c|c|c|}
\hline Country Group & BRCA1 & BRCA2 & Unaffected & Breast Cancer & ER- & ER+ & PR- & PR+ \\
\hline$\overline{\text { Austria }^{1}}$ & 465 & 179 & 318 & 326 & 76 & 51 & 76 & 44 \\
\hline Australia $^{2}$ & 660 & 552 & 541 & 671 & 235 & 200 & 297 & 121 \\
\hline Canada $^{3}$ & 443 & 358 & 386 & 415 & 107 & 70 & 89 & 68 \\
\hline Denmark $^{4}$ & 507 & 319 & 463 & 363 & 98 & 93 & 79 & 45 \\
\hline France-Belgium-Spain ${ }^{5}$ & 1,673 & 1,256 & 1,217 & 1,712 & 140 & 165 & 1,661 & 127 \\
\hline Finland $^{6}$ & 103 & 105 & 91 & 117 & 59 & 54 & 74 & 39 \\
\hline Germany $^{7}$ & 1,231 & 589 & 648 & 1,172 & 443 & 336 & 457 & 311 \\
\hline Iceland $^{8}$ & 0 & 135 & 24 & 111 & 21 & 57 & 18 & 57 \\
\hline Italy ${ }^{9}$ & 994 & 666 & 686 & 974 & 203 & 251 & 231 & 216 \\
\hline Latvia-Lithuania-Russia $^{10}$ & 190 & 0 & 79 & 111 & 21 & 6 & 18 & 7 \\
\hline Sweden $^{11}$ & 537 & 177 & 396 & 318 & 86 & 54 & 89 & 50 \\
\hline Netherlands ${ }^{12}$ & 804 & 319 & 611 & 512 & 72 & 41 & 69 & 29 \\
\hline UK-Eire ${ }^{13}$ & 1,107 & 866 & 1,008 & 965 & 268 & 239 & 175 & 104 \\
\hline USA $^{14}$ & 2,707 & 1559 & 2,118 & 2048 & 482 & 366 & 512 & 297 \\
\hline Total & 11,421 & 7,080 & 8,686 & 9,815 & 2,311 & 1,983 & 2,345 & 1,515 \\
\hline
\end{tabular}

Studies in country groups:1:MUV; 2:BCFR/KCONFAB; 3:OCGN/BCFR/INHERIT; 4:CBCS/OUH; 5: GEMO/CNIO/HCSC/ICO/MOD-SQUAD; 6:HEBCS; 7:GC-HBOC/DKFZ; 8: ILUH; 9:CONSIT-TEAM/IOVHBOCS/PBCS; 10: NNPIO/BFBOCC; 11: SWE-BRCA; 12: HEBON; 13:EMBRACE/UKGRFOCR; 14:FCCC/GEMO/GEORGETOWN/MAGIC/MAYO/ MSKCC/NCI/OSU-CCG/UCI/UCSF/UKGRFOCR/UPENN/WCRI

proportion and intensity of staining were available (Allred score, Remmele score and H-score), widelyaccepted cut-offs were used (Additional file 1, Table S2). Consistency checks were performed to validate receptor data against supplementary scoring information if provided.

\section{Genotyping}

This analysis included genotype data on 12 SNPs that had been previously assessed for their associations with the overall risk of breast cancer for $B R C A 1$ and BRCA2 mutation carriers in CIMBA. Genotyping was performed using either the iPLEX or Taqman platforms and has been described in detail in the previous reports [28-31]. To ensure genotyping consistency, all genotyping centres were required to adhere to the CIMBA genotyping quality control criteria which are described in detail online [34]. The 12 SNPs genotyped were rs2981582 in FGFR2, rs3803662 in TOX3/ TNRC9, rs889312 in MAP3K1, rs3817198 in LSP1, rs13387042 at $2 \mathrm{q} 35, \mathrm{rs} 13281615$ at $8 \mathrm{q} 24, \mathrm{rs} 4973768$ near SLC4A7/NEK10, rs6504950 in the STXBP4/ COX11 region, rs2046210 near ESR1 at 6q25.1 and rs11249433 at 1 p11.2. A Taqman assay could not be adequately designed for SNP rs999737 in the RAD51L1 region and studies using this platform genotyped the surrogate SNP rs10483813 (pair-wise $\mathrm{r}^{2}=1$ with rs999737 based on HapMap CEU data). Data for these two SNPs were combined and treated as a single locus in the analysis of associations.

\section{Statistical analysis}

The aim of this study was to evaluate the associations between each genotype and breast cancer subtypes defined by tumour characteristics in BRCA1 and BRCA2 mutation carriers separately. The phenotype of each individual was defined by the age at diagnosis of breast cancer and its subtype or by age at last follow-up. Individuals were censored at the age of the first breast cancer diagnosis, ovarian cancer diagnosis, or bilateral prophylactic mastectomy or the age at last observation. Mutation carriers censored at ovarian cancer diagnosis were considered unaffected.

The analysis of risk modifiers in BRCA1 and BRCA2 mutation carriers is complicated by the fact that mutation carriers are not randomly sampled with respect to their disease status. Many carriers are sampled through families seen in genetic clinics. The first tested individual in a family is usually someone diagnosed with cancer at a relatively young age. Such study designs, therefore, tend to lead to an over-sampling of affected individuals, and standard analytical methods like Cox regression or case-control analysis may lead to biased estimates of the risk ratios [35]. This can be illustrated by considering an individual affected at age $t$. In a standard analysis of a cohort study or a case-control analysis, the SNP genotype for the individual will be compared with those of all individuals at risk at age $t$ or in a case-control analysis, with controls randomly sampled from all possible at risk individuals. This analysis leads to consistent estimates of the hazard ratio or 
odds ratio estimates. However, in the present design, mutation carriers are already selected on the basis of disease status (where affected individuals are oversampled). If standard cohort analysis were applied to these data, it would lead to affected individuals at age $t$ being compared to unaffected carriers selected on the basis of their future disease status. If the genotype is associated with the disease, the risk estimate will be biased to zero because too many affected individuals (in whom the at-risk genotype is overrepresented) are included in the comparison group. Simulation studies have shown that this effect can be quite marked [35]. To address this, a retrospective likelihood approach was previously proposed, which models the observed genotypes conditional on the disease phenotypes [36]. For the current analyses we have extended this method to model the simultaneous effect of each SNP on more than one tumour subtype. We briefly describe this method for the analysis of associations with ER-positive and ER-negative breast cancer, but the same principles apply for the analysis of associations with other tumour characteristics.

We modelled the likelihood of the observed genotypes and tumour subtype conditional on the disease status, that is:

$$
\prod_{i=1}^{n} P\left(g_{i}, d_{i} \mid \gamma\left(t_{i}\right)\right)=\prod_{i}^{n} \frac{P\left(\left(\gamma\left(t_{i}\right), d_{i} \mid g_{i}\right)\right) P\left(g_{i}\right)}{P\left(\gamma\left(t_{i}\right)\right)}
$$

Where $y\left(t_{i}\right)$ is the disease phenotype for individual $i$ at censoring age $t_{i}$ (breast cancer at age $t_{i}$ or unaffected at age $\left.t_{i}\right), d_{i}$ is the ER status ( $0=$ negative, $1=$ positive $)$ and $g_{i}$ the observed genotype of individual $i\left(g_{i}=0,1\right.$ or 2 minor alleles) and $n$ the number of subjects in the analysis. To allow for tumour characteristics we assumed that breast cancer consists of different disease subtypes, such that the total breast cancer incidence at age $t_{i}, \lambda\left(t_{i}\right)$, is the sum of the disease incidence for the subtypes, that is $\lambda\left(t_{i}\right)=v\left(t_{i}\right)+\mu\left(t_{i}\right)$, where $v\left(t_{i}\right)$ is the incidence for ER-negative disease and $\mu\left(t_{i}\right)$ is the incidence of ER-positive disease. We assumed that the subtype-specific incidences depend on the underlying genotype through a Cox-proportional hazards model: $v\left(t_{i}\right)=v_{0}\left(t_{i}\right) \exp \left(\beta^{t} \mathbf{z}_{g_{i}}\right)$ and $\mu\left(t_{i}\right)=\mu_{0}\left(t_{i}\right) \exp \left(\gamma^{t} \mathbf{z}_{g_{i}}\right)$ where $v_{0}\left(t_{i}\right)$ and $\mu_{0}\left(t_{i}\right)$ and are the baseline incidences for disease subtypes (ER-negative and ER-positive respectively), $\mathbf{z}_{g_{i}}$ is the genotype vector for individual $i$ and $\beta$ and $\gamma$ are the subtype specific genotype log-risk ratios (for ER-negative and ER-positive breast cancer respectively). The probabilities of developing ER-positive and ER-negative breast cancer conditional on the underlying genotype were assumed to be independent. We further assumed that, if tumour subtype is unknown, the information is missing at random with respect to genotype. Then for each individual:

$$
\begin{aligned}
= & \left(v_{0}\left(t_{i}\right) \exp \left(\beta^{t} \mathbf{z}_{z_{i}}\right)\right)^{O_{i}\left(1-d_{i}\right)} \times\left(\mu_{0}\left(t_{i}\right) \exp \left(\gamma^{t} \mathbf{z}_{\mathbf{z}_{i}}\right)\right)^{O_{i} d_{i} \times} \\
P\left(\left(\gamma\left(t_{i}\right), d_{i} \mid g_{i}\right)\right)= & \exp \left(-\sum_{u=0}^{t_{i}-1}\left(\mu_{0}(u) \exp \left(\gamma^{t} \mathbf{z}_{z_{i}}\right)+v_{0}(u) \exp \left(\beta^{t} \mathbf{z}_{z_{i}}\right)\right)\right) \text { if } d_{i}=0,1 \\
= & \left(\mu_{0}\left(t_{i}\right) \exp \left(\gamma^{t} \mathbf{z}_{z_{i}}\right)+v_{0}(t) \exp \left(\beta^{t} \mathbf{z}_{\mathbf{z}_{i}}\right)\right)^{O_{i} \times} \\
& \exp \left(-\sum_{u=0}^{t_{i}-1}\left(\mu_{0}(u) \exp \left(\gamma^{t} \mathbf{z}_{z_{i}}\right)+v_{0}(u) \exp \left(\beta^{t} \mathbf{z}_{z_{i}}\right)\right)\right) \text { if } d_{i}=\text { unknown }
\end{aligned}
$$

were $O_{i}=0$ if unaffected and $O_{i}=1$ if affected. Thus, the above formulation allows use of all mutation carriers irrespective of whether the tumour subtype is observed or not. The baseline incidences for each disease subtype $\left(v_{0}\left(t_{i}\right)\right.$ and $\left.\mu_{0}\left(t_{i}\right)\right)$ are unknown. However, it is possible to solve for those recursively by constraining the overall breast cancer incidence for mutation carriers $\lambda(t)$, to agree with external estimates as previously demonstrated $[37,38]$ and by imposing a further constraint on the ratio of the observed ER-positive to ER-negative breast cancers in each age group:

$$
\begin{aligned}
& \frac{P(\text { ERpositive at age } t)}{P(\text { ERnegative at age } t)}=\frac{\pi_{+}(t)}{\pi_{-}(t)}= \\
& =\frac{\sum_{g} P(g) \mu_{0}(t) \exp \left(\gamma^{t} \mathbf{z}_{g}\right) \exp \left(-\sum_{u=0}^{t-1}\left(\mu_{0}(u) \exp \left(\gamma^{t} \mathbf{z}_{g}\right)+v_{0}(u) \exp \left(\beta^{t} \mathbf{z}_{g}\right)\right)\right)}{\sum_{g} P(g) v_{0}(t) \exp \left(\beta^{t} \mathbf{z}_{g}\right) \exp \left(-\sum_{u=0}^{t-1}\left(\mu_{0}(u) \exp \left(\gamma^{t} \mathbf{z}_{g}\right)+v_{0}(u) \exp \left(\beta^{t} \mathbf{z}_{g}\right)\right)\right)}
\end{aligned}
$$

The likelihood in equation 1 can then be maximised jointly over the log-risk ratios $\boldsymbol{\beta}$ and $\boldsymbol{\gamma}$, genotype frequencies $P(g)$ and the age and subtype-specific frequencies $\pi_{+}(t)$ and $\pi_{-}(t)$ This likelihood is based on the assumption that the ascertainment of mutation carriers is dependent on the overall disease phenotype (breast cancer) but not on tumour subtypes. This allows the subtype frequencies $\pi_{+}(t)$ and $\pi_{-}(t)$ to be estimated within the dataset. Relaxing this assumption and conditioning also on tumour subtype requires external estimates for the age and subtype-specific frequencies $\pi_{+}(t)$ and $\pi_{-}(t)$.

The effect of each SNP was modelled either as a perallele HR (multiplicative model) or as separate HRs for heterozygotes and homozygotes, and these were estimated on the logarithmic scale. Heterogeneity in the hazard ratios between tumour subtypes was examined by fitting models where $v\left(t_{i}\right)=v_{0}\left(t_{i}\right) \exp \left(\beta_{1 g}\right)$ and $\mu\left(t_{i}\right)$ $=\mu_{0}\left(t_{i}\right) \exp \left(\beta_{1}+\beta_{2}\right) g$ ) with $g=0,1$ and 2 (for $0,1,2$ copies of the minor allele respectively) and testing for $\beta_{2}$ $=0$. Analyses were carried out with the pedigree-analysis software MENDEL [39]. All analyses were stratified by country of residence and used calendar-year- and cohort-specific cancer incidences for BRCA1 and $B R C A 2$ [40]. For this purpose, a stratified version of the retrospective likelihood (equation 1) was derived as described previously [36]. Countries with small numbers 
of mutation carriers were grouped together. We used a robust variance-estimation approach to allow for the non-independence among related mutation carriers [41].

\section{Predicted breast cancer risks by ER status}

Based on our results we computed the predicted absolute risk of developing ER-negative and ER-positive breast cancer for $B R C A 1$ and BRCA2 mutation carriers by the combined 12 SNP profile. For each individual we derived an empirical score, based on the per-allele logrelative hazard estimates for each genotype, which was of the form $\sum_{j=1}^{12} \beta_{j} g_{j}$ where $\beta_{j}$ is the per-allele log-hazard estimate for locus $\mathrm{j}$ and $g_{j}$ is the genotype at the same locus (taking values 0,1 and 2). This assumes a multiplicative model for the combined SNP associations. This is a reasonable assumption given that previous analyses found no evidence of departure from the multiplicative model [35]. Scores were calculated for ER-positive and ER-negative disease, separately for BRCA1 and BRCA2 mutation carriers. The empirical distribution of the derived score was then used to compute the subtype specific incidence associated with each multilocus genotype as described previously [31]. We reported the absolute risks of developing ER-specific breast cancer at the $5^{\text {th }}, 50^{\text {th }}$ and $95^{\text {th }}$ percentiles of the empirical distribution of the SNP profile.

\section{Results}

A total of 11,421 BRCA1 and 7,080 BRCA2 mutation carriers from 36 studies had been successfully genotyped for at least one of the12 SNPs and were eligible for inclusion in these analyses. 9,815 BRCA1 and BRCA2 mutation carriers were censored at a first invasive breast cancer diagnosis, of whom 4,310 had information on either ER or PR (Table 1).

\section{Associations with ER status - BRCA1 mutation carriers}

There were significant differences in the HR for ERpositive and ER-negative disease for BRCA1 mutation carriers for two SNPs (Table 2). The FGFR2 SNP rs2981582 exhibited the clearest difference with a strong association for ER-positive disease but not ER-negative disease (per allele $\mathrm{HR}=1.35,95 \% \mathrm{CI}: 1.17$ to 1.56 , for ER-positive compared with $\mathrm{HR}=0.91,95 \% \mathrm{CI}: 0.85$ to 0.98 for ER-negative, $P$-heterogeneity $\left.=6.5 \times 10^{-6}\right)$. The SLC4A7/NEK10 SNP rs4973768 also exhibited a similar pattern (ER-positive: per-allele $\mathrm{HR}=1.17,95 \% \mathrm{CI}: 1.03$ to 1.133 , compared with ER-negative: per-allele $\mathrm{HR}=$ 0.99, 95\% CI: 0.93 to $1.06, P$-heterogeneity $=0.027$ ). Although there was no significant evidence of differences between the HRs for ER-positive and ER-negative breast cancer, the TOX3/TNRC9 SNP rs3803662 was significantly associated with the risk of ER-positive disease (per-allele $\mathrm{HR}=1.25,95 \% \mathrm{CI}: 1.06$ to $.46, P$-trend $=0.0062$ ) but not with risk for ER-negative breast cancer $($ per-allele $\mathrm{HR}=1.05,95 \% \mathrm{CI}$ : 0.97 to $1.13, P$-trend $=0.21)$. LSP1 SNP rs3817198 was associated with the risk of ER-negative breast cancer (per-allele HR $=1.07$, 95\% CI: 1.00 to $1.07, P$-trend $=0.047$ ) but not with risk of ER-positive breast cancer (per-allele HR $=1.07$, 95\% CI: 0.93 to $1.22, P$-trend $=0.33, P$-het $=0.98)$. The 6q25.1 SNP rs2046210 near ESR1 was associated with the risk for both ER-negative (per-allele HR $=1.19$, 95\% CI: 1.11 to $1.27, P$-trend $=2.4 \times 10^{-7}$ ) and ER-positive (per-allele $\mathrm{HR}=1.14,95 \% \mathrm{CI}: 1.01$ to $1.30, P$-trend $=$ 0.043 ) breast cancer. There was no significant evidence of association with either ER-negative or ER-positive breast cancer for any of the other SNPs, although the HR estimates tended to be higher for ER-positive breast cancer (for example, SNPs rs13387042 at 2q35 and rs13281615 at $8 \mathrm{q} 24)$.

\section{Associations with ER status - BRCA2 mutation carriers}

Only SNP rs2046210 at 6q25.1 exhibited differential associations between ER-positive and ER-negative breast cancer for BRCA2 mutation carriers ( $P$-heterogeneity = 0.045, Table 3). The per-allele HR for ER-negative disease was estimated to be 1.17 (95\% CI: 0.99 to 1.38 ) whereas the per-allele HR for ER-positive breast cancer was 0.97 (95\% CI: 0.89 to 1.05). Although there were no significant differences in the associations between the two types of disease for BRCA2 mutation carriers, the $\mathrm{HR}$ estimates for ER-positive disease tended to be larger compared to ER-negative breast cancer. SNPs at/near FGFR2, TOX3/TNRC9, MAP3K1, LSP1, 2q35, SLC4A7/ NEK10, 5p12 and 1p11.2 were associated with ER-positive breast cancer for BRCA2 mutation carriers (using either a per-allele or $2 \mathrm{df}$ genotype test). The strongest associations were for the FGFR2 rs2981582 SNP (HR for ER-positive breast cancer $=1.35,95 \% \mathrm{CI}: 1.23$ to 1.48 , $P$-trend $\left.=1.4 \times 10^{-10}\right)$ and TOX3/TNRC9 SNP rs3803662 (HR for ER-positive breast cancer $=1.28$. 95\% CI: 1.16 to $1.41, P$-trend $\left.=1.5 \times 10^{-6}\right)$. Only SNPs at or near MAP3K1, STXBP4/COX11 and 6 q25.1 were associated with the risk of ER-negative breast cancer for BRCA2 mutation carriers.

\section{Associations with PR status - BRCA1 mutation carriers}

The general pattern of associations with PR-positive and PR-negative breast cancer for BRCA1 mutation carriers (Additional file 1, Table S3) was similar to that seen for ER status. Significant differences in the associations between PR-positive and PR-negative breast cancer were observed for three SNPs. The minor allele of FGFR2 SNP rs2981582 was associated with a significantly higher risk for PR-positive breast cancer for $B R C A 1$ 
Table 2 Genotype and per-allele hazard ratio estimates by estrogen receptor status for BRCA1 mutation carriers

\begin{tabular}{|c|c|c|c|c|c|c|c|c|c|c|c|}
\hline \multirow[t]{2}{*}{ Genotype } & \multirow{2}{*}{$\begin{array}{c}\text { Unaffected, } \\
\text { N (\%) }\end{array}$} & \multicolumn{3}{|c|}{ Affected by subtype, N (\%) } & \multicolumn{3}{|c|}{ ER- } & \multicolumn{3}{|c|}{ ER+ } & \multirow[t]{2}{*}{$P$-het } \\
\hline & & ER- & ER+ & Unknown & HR & $95 \% \mathrm{Cl}$ & P-trend & HR & $95 \% \mathrm{Cl}$ & P-trend & \\
\hline \multicolumn{12}{|c|}{ FGFR2 rs2981582 } \\
\hline GG & $1301(36.2)$ & $447(40.0)$ & 104 (29.6) & $869(35.1)$ & 1.00 & & & 1.00 & & & \\
\hline GA & $1,721(47.9)$ & $516(46.2)$ & $166(47.3)$ & $1190(48.1)$ & 0.93 & 0.83 to 1.03 & & 1.24 & 0.98 to 1.57 & & \\
\hline AA & $573(15.9)$ & $154(13.8)$ & $81(23.1)$ & $416(16.8)$ & 0.82 & 0.70 to 0.96 & & 1.85 & 1.40 to 2.44 & & \\
\hline Per-allele & & & & & 0.91 & 0.85 to 0.98 & 0.01 & 1.35 & 1.17 to 1.56 & $4 \times 10^{-5}$ & $6.5 \times 10^{-6}$ \\
\hline \multicolumn{12}{|c|}{ TOX3/TNRC9 rs3803662 } \\
\hline CC & $1,811(52.0)$ & $545(49.5)$ & $154(45.7)$ & $1195(50.2)$ & 1.00 & & & 1.00 & & & \\
\hline CT & $1,405(40.3)$ & $461(41.8)$ & $143(42.4)$ & $987(41.5)$ & 1.06 & 0.96 to 1.18 & & 1.20 & 0.97 to 1.50 & & \\
\hline$\pi$ & $269(7.7)$ & $96(8.7)$ & $40(11.9)$ & $199(8.4)$ & 1.09 & 0.90 to 1.31 & & 1.61 & 1.14 to 2.27 & & \\
\hline Per-allele & & & & & 1.05 & 0.97 to 1.13 & 0.21 & 1.25 & 1.06 to 1.46 & 0.0062 & 0.07 \\
\hline \multicolumn{12}{|c|}{ MAP3K1 rs889312 } \\
\hline AA & $1,858(49.6)$ & $569(49.7)$ & $186(52.1)$ & 1319 (51.6) & 1.00 & & & 1.00 & & & \\
\hline$A C$ & $1,552(41.4)$ & 480 (41.9) & $136(38.1)$ & 987 (38.6) & 0.97 & 0.87 to 1.07 & & 0.86 & 0.69 to 1.06 & & \\
\hline $\mathrm{CC}$ & $336(9.0)$ & $97(8.5)$ & $35(9.8)$ & $250(9.8)$ & 0.97 & 0.81 to 1.16 & & 0.97 & 0.69 to 1.35 & & \\
\hline Per-allele & & & & & 0.98 & 0.91 to 1.06 & 0.56 & 0.97 & 0.83 to 1.13 & 0.69 & 0.92 \\
\hline \multicolumn{12}{|l|}{ LSP1 rs3817198 } \\
\hline$\pi$ & $1,894(47.4)$ & $652(45.4)$ & $195(44.5)$ & 1205 (43.7) & 1.00 & & & 1.00 & & & \\
\hline $\mathrm{TC}$ & $1,680(42.0)$ & $629(43.8)$ & 197 (45.0) & $1239(44.9)$ & 1.09 & 0.99 to 1.20 & & 1.11 & 0.92 to 1.35 & & \\
\hline CC & $422(10.6)$ & $154(10.7)$ & $46(10.5)$ & $315(11.4)$ & 1.13 & 0.97 to 1.33 & & 1.10 & 0.80 to 1.50 & & \\
\hline Per-allele & & & & & 1.07 & 1.00 to 1.15 & 0.047 & 1.07 & 0.93 to 1.22 & 0.33 & 0.98 \\
\hline \multicolumn{12}{|c|}{$2 q 35$ rs13387042 } \\
\hline GG & $924(24.0)$ & $301(22.1)$ & $93(22.2)$ & $576(21.4)$ & 1.00 & & & 1.00 & & & \\
\hline GA & $1,855(48.3)$ & $723(53.1)$ & $194(46.3)$ & $1370(50.9)$ & 1.17 & 1.04 to 1.32 & & 1.02 & 0.81 to 1.30 & & \\
\hline AA & $1,064(27.7)$ & $338(24.8)$ & $132(31.5)$ & $745(27.7)$ & 0.96 & 0.84 to 1.11 & & 1.25 & 0.97 to 1.62 & & \\
\hline Per-allele & & & & & 0.98 & 0.91 to 1.04 & 0.48 & 1.13 & 0.99 to 1.28 & 0.075 & 0.065 \\
\hline \multicolumn{12}{|c|}{$8 q 24$ rs13281615 } \\
\hline AA & $1,319(32.8)$ & $502(35.9)$ & $143(33.7)$ & $897(32.5)$ & 1.00 & & & 1.0 & & & \\
\hline$A G$ & $2,008(50.0)$ & $657(47.0)$ & $198(46.7)$ & $1,364(49.5)$ & 0.98 & 0.88 to 1.08 & & 0.97 & 0.79 to 1.19 & & \\
\hline GG & $691(17.9)$ & $238(17.0)$ & $83(19.6)$ & $496(18.0)$ & 1.00 & 0.87 to 1.16 & & 1.17 & 0.89 to 1.53 & & \\
\hline Per-allele & & & & & 1.00 & 0.93 to 1.07 & 0.93 & 1.06 & 0.93 to 1.22 & 0.38 & 0.43 \\
\hline \multicolumn{12}{|c|}{ SLC4A7/NEK10 rs4973768 } \\
\hline $\mathrm{CC}$ & $1,148(26.2)$ & $406(27.2)$ & $103(22.2)$ & $691(24.7)$ & 1.00 & & & 1.00 & & & \\
\hline$C T$ & 2,205 (50.4) & $736(49.3)$ & $235(50.5)$ & $1,399(50.1)$ & 0.98 & 0.88 to 1.08 & & 1.20 & 0.96 to 1.51 & & \\
\hline$\pi$ & $1,024(23.4)$ & $350(23.5)$ & $127(27.3)$ & $703(25.2)$ & 0.99 & 0.87 to 1.12 & & 1.38 & 1.07 to 1.77 & & \\
\hline Per-allele & & & & & 0.99 & 0.93 to 1.06 & 0.83 & 1.17 & 1.03 to 1.33 & 0.013 & 0.027 \\
\hline \multicolumn{12}{|c|}{ STXBP4/COX11 rs6504950 } \\
\hline GG & $2,346(53.1)$ & $814(53.2)$ & $252(52.9)$ & $1,502(53.1))$ & 1.00 & & & 1.00 & & & \\
\hline GA & $1,737(39.3)$ & $593(37.8)$ & $191(40.1)$ & $1,127(39.8)$ & 1.00 & 0.91 to 1.10 & & 1.03 & 0.86 to 1.24 & & \\
\hline AA & $333(7.5)$ & $122(8.0)$ & $33(6.9)$ & $200(7.1)$ & 1.04 & 0.88 to 1.23 & & 0.94 & 0.65 to 1.34 & & \\
\hline Per-allele & & & & & 1.01 & 0.94 to 1.09 & 0.77 & 1.00 & 0.87 to 1.15 & 0.97 & 0.87 \\
\hline \multicolumn{12}{|c|}{ 5p12 rs10941679 } \\
\hline AA & 2,211 (55.8) & $815(57.3)$ & $271(61.0)$ & $1,529(56.5)$ & 1.00 & & & 1.00 & & & \\
\hline$A G$ & $1,472(37.1)$ & $517(36.4)$ & $145(32.7)$ & $1,001(37.0)$ & 0.99 & 0.90 to 1.09 & & 0.84 & 0.69 to 1.02 & & \\
\hline GG & $280(7.1)$ & $90(6.3)$ & $28(6.3)$ & $177(6.5)$ & 0.89 & 0.73 to 1.08 & & 0.84 & 0.58 to 1.20 & & \\
\hline Per-allele & & & & & 0.97 & 0.90 to 1.04 & 0.39 & 0.88 & 0.75 to 1.02 & 0.08 & 0.26 \\
\hline \multicolumn{12}{|c|}{$6 q 25.1-r s 2046210$} \\
\hline $\mathrm{CC}$ & $1,886(43.3)$ & $567(38.2)$ & $158(36.0)$ & $1,007(37.0)$ & 1.00 & & & 1.00 & & & \\
\hline $\mathrm{TC}$ & $1,919(44.1)$ & $718(48.3)$ & $232(52.9)$ & $1,305(48.0)$ & 1.21 & 1.10 to 1.33 & & 1.37 & 1.13 to 1.67 & & \\
\hline$\pi$ & $547(12.6)$ & $201(13.5)$ & $49(11.2)$ & $409(15.0)$ & 1.39 & 1.21 to 1.59 & & 1.11 & 0.81 to 1.53 & & \\
\hline Per-allele & & & & & 1.19 & 1.11 to 1.27 & $2.4 \times 10^{-7}$ & 1.14 & 1.01 to 1.30 & 0.043 & 0.60 \\
\hline
\end{tabular}


Table 2 Genotype and per-allele hazard ratio estimates by estrogen receptor status for BRCA1 mutation carriers (Continued)

\begin{tabular}{|c|c|c|c|c|c|c|c|c|c|c|c|}
\hline \multicolumn{12}{|c|}{$1 p 11.2-r s 11249433$} \\
\hline$\pi$ & $1,491(34.1)$ & $506(33.7)$ & $144(32.4)$ & $973(35.1)$ & 1.00 & & & 1.00 & & & \\
\hline CT & $2,133(48.7)$ & $745(49.7)$ & $245(55.2)$ & $1,342(48.5)$ & 0.97 & 0.88 to 1.07 & & 1.10 & 0.90 to 1.34 & & \\
\hline CC & $752(17.2)$ & $248(16.5)$ & $55(12.4)$ & $455(16.4)$ & 0.99 & 0.87 to 1.13 & & 0.76 & 0.56 to 1.03 & & \\
\hline Per-allele & & & & & 0.99 & 0.93 to 1.06 & 0.79 & 0.92 & 0.81 to 1.05 & 0.22 & 0.35 \\
\hline \multicolumn{12}{|c|}{ RAD51L1 - rs999737/rs10483813 } \\
\hline $\mathrm{CC} / \mathrm{TT}$ & 2,335 (61.5) & $760(64.1)$ & $212(62.5)$ & $1,551(62.5)$ & 1.00 & & & 1.00 & & & \\
\hline TC/AT & $1,294(34.1)$ & $370(31.2)$ & $113(33.3)$ & $819(33.0)$ & 0.92 & 0.83 to 1.03 & & 1.00 & 0.80 to 1.24 & & \\
\hline TT/AA & $170(4.5)$ & $56(4.7)$ & $14(4.1)$ & $110(4.4)$ & 1.02 & 0.81 to 1.28 & & 0.93 & 0.56 to 1.56 & & \\
\hline per allele & & & & & 0.96 & 0.88 to 1.04 & 0.34 & 0.98 & 0.82 to 1.18 & 0.87 & 0.81 \\
\hline
\end{tabular}

$P$-het, Heterogeneity $P$-value; ER-, estrogen receptor negative; ER+, estrogen receptor positive

mutation carriers (per-allele HR for PR-positive $=1.29$, 95\% CI: 1.10 to 1.51, HR for PR-negative $=0.93,95 \%$ CI: 0.87 to 1.00 , P-heterogeneity $=7 \times 10^{-4}$ ). Allele "A" of SNP rs13387042 at 2q35 was associated with a significantly higher risk of PR-positive breast cancer for BRCA1 mutation carriers (HR for PR-positive breast cancer $=1.16,95 \%$ CI: 1.01 to 1.33 ; HR for PR-negative $=0.97,95 \%$ CI: 0.91 to $1.04, P$-heterogeneity $=0.034$ ). Although the RAD51L1 SNP showed no differential associations with ER-status, there was evidence that the minor allele of this SNP was associated with a lower risk of PR-positive breast cancer ( $\mathrm{HR}$ for PR-positive = 0.79, 95\% CI: 0.61 to 0.95 ; HR for PR-negative $=1.02$, 95\% CI: 0.94 to $1.11 ; P$-heterogeneity $=0.027)$. The only SNPs associated with risk for PR-negative breast cancer were SNPs at 6q25.1 (per-allele HR $=1.19,95 \% \mathrm{CI}: 1.11$ to $1.27, P$-trend $\left.=3.7 \times 10^{-7}\right)$, and in LSP1 (per-allele $\mathrm{HR}=1.09,95 \% \mathrm{CI}: 1.01$ to $1.16, P$-trend $=0.017)$, but these were not significantly different from the associations with PR-positive breast cancer for BRCA1 mutation carriers.

\section{Associations with PR status - BRCA2 mutation carriers}

Only two SNPs demonstrated significant differences in the associations with PR-positive and PR-negative breast cancer for BRCA2 mutation carriers (Additional file 1, Table S4). SNP rs13387042 at $2 \mathrm{q} 35$ was associated with a higher risk of PR-positive breast cancer (per-allele HR for PR-positive $=1.14,95 \%$ CI: 1.03 to 1.25 ; per-allele HR for PR-negative $=0.92,95 \% \mathrm{CI}: 0.81$ to $1.04, P$-heterogeneity $=0.009)$. SNP rs10941679 at $5 \mathrm{p} 12$ was also associated with a higher risk of PR-positive breast cancer for BRCA2 mutation carriers (per-allele HR for PRpositive $=1.15$. 95\% CI: 1.03 to 1.27 , HR for PR-negative $=0.94,95 \% \mathrm{CI}: 0.81$ to $1.09, P$-heterogeneity $=0.028$ ). SNPs near or at FGFR2, TOX3/TNRC9, LSP1 were associated with both PR-negative and PR-positive breast cancer, whereas the 1p11.2 SNP was associated with risk for PR-negative breast cancer. MAP3K1 and SLC4A7/
NEK10 were associated only with risk of PR-positive breast cancer among BRCA2 mutation carriers.

\section{Absolute risks of developing ER-positive and ER-negative breast cancer by SNP profile}

Using the estimated HRs for ER-positive and ER-negative breast cancer for BRCA1 and BRCA2 mutation carriers, we computed the predicted absolute risk of developing ER-negative and ER-positive breast cancer at various percentiles of the combined SNP distribution. The SNP profile distribution is different for each disease subtype and mutation. We note that SNPs for which the per-allele HR estimates are close to 1.0 contribute little to the predicted ER-specific risks. Figure 1 shows the predicted risks of developing ER-negative and ER-positive breast cancer for $B R C A 1$ and $B R C A 2$ mutation carriers at the $5^{\text {th }}, 50^{\text {th }}$ and $95^{\text {th }}$ percentiles of the empirical risk distribution of the combined SNP profile. A BRCA1 mutation carrier at the $5^{\text {th }}$ percentile of the SNP profile distribution would be at $43 \%$ risk of developing ERnegative breast cancer by age 80 compared with $60 \%$ for BRCA 1 mutation carriers at the $95^{\text {th }}$ percentile of the risk distribution. The risks of developing ER-positive breast cancer would be $18 \%$ and $46 \%$ by age 80 at the $5^{\text {th }}$ and $95^{\text {th }}$ percentiles of the ER-positive breast cancer risk distribution. BRCA2 mutation carriers at the $5^{\text {th }}$ percentile of the ER-negative breast cancer risk distribution are predicted to have a $22 \%$ risk of developing ERnegative breast cancer by age 80 compared with $39 \%$ for the $95^{\text {th }}$ percentile of the risk distribution. The risks of developing ER-positive breast cancer by age 80 for $B R C A 2$ carriers varied from $33 \%$ to $70 \%$ at the $5^{\text {th }}$ and $95^{\text {th }}$ percentiles of the ER-positive risk distribution respectively.

\section{Discussion}

This is the first report to investigate the associations between 12 common breast cancer susceptibility alleles and ER and PR status of breast tumours in BRCA1 and 
Table 3 Genotype and per-allele hazard ratio estimates by estrogen receptor status for $B R C A 2$ mutation carriers

\begin{tabular}{|c|c|c|c|c|c|c|c|c|c|c|c|}
\hline \multirow[t]{2}{*}{ Genotype } & \multirow{2}{*}{$\begin{array}{c}\text { Unaffected, } \\
\text { N (\%) }\end{array}$} & \multicolumn{3}{|c|}{ Affected by subtype, N (\%) } & \multicolumn{3}{|c|}{ ER- } & \multicolumn{3}{|c|}{ ER+ } & \multirow[t]{2}{*}{$P$-het } \\
\hline & & ER- & $\mathrm{ER}+$ & Unknown & HR & $95 \% \mathrm{Cl}$ & $\begin{array}{c}P- \\
\text { trend }\end{array}$ & $H R$ & $95 \% \mathrm{Cl}$ & P-trend & \\
\hline \multicolumn{12}{|c|}{ FGFR2 rs2981582 } \\
\hline GG & $794(37.8)$ & $86(32.7)$ & $\begin{array}{c}248 \\
(29.5)\end{array}$ & $457(29.8)$ & 1.00 & & & 1.00 & & & \\
\hline GA & $987(47.0)$ & $137(52.1)$ & $\begin{array}{c}419 \\
(49.8)\end{array}$ & $755(49.3)$ & 1.28 & 0.99 to 1.67 & & 1.35 & 1.17 to 1.55 & & \\
\hline AA & $321(15.3)$ & $40(15.2)$ & $\begin{array}{c}174 \\
(20.7)\end{array}$ & $320(20.9)$ & 1.23 & 0.85 to 1.78 & & 1.81 & 1.51 to 2.18 & & \\
\hline Per-allele & & & & & 1.14 & 0.97 to 1.35 & 0.12 & 1.35 & 1.23 to 1.48 & $1.4 \times 10^{-10}$ & 0.097 \\
\hline \multicolumn{12}{|c|}{ TOX3/TNRC9 rs3803662 } \\
\hline $\mathrm{CC}$ & $1,088(53.4)$ & $136(53.3)$ & $\begin{array}{c}377 \\
(46.3)\end{array}$ & $702(48.2)$ & 1.00 & & & 1.00 & & & \\
\hline CT & $792(38.9)$ & $96(37.7)$ & $\begin{array}{c}361 \\
(44.3)\end{array}$ & $604(41.5)$ & 0.98 & 0.75 to 1.27 & & 1.33 & 1.17 to 1.53 & & \\
\hline$\pi$ & $157(7.7)$ & $23(9.0)$ & $77(9.5)$ & $150(10.3)$ & 1.27 & 0.83 to 1.93 & & 1.54 & 1.22 to 1.95 & & \\
\hline Per-allele & & & & & 1.06 & 0.88 to 1.29 & 0.53 & 1.28 & 1.16 to 1.41 & $1.5 \times 10^{-6}$ & 0.11 \\
\hline \multicolumn{12}{|c|}{ MAP3K1 rs889312 } \\
\hline AA & $1,107(51.1)$ & $121(45.7)$ & $\begin{array}{c}430 \\
(50.3)\end{array}$ & $746(47.7)$ & 1.00 & & & 1.00 & & & \\
\hline$A C$ & $888(41.0)$ & $120(45.3)$ & $\begin{array}{c}349 \\
(40.8)\end{array}$ & $646(41.3)$ & 1.23 & 0.96 to 1.59 & & 1.03 & 0.90 to 1.17 & & \\
\hline $\mathrm{CC}$ & $170(7.9)$ & $24(9.1)$ & $76(8.9)$ & $172(11.0)$ & 1.42 & 0.93 to 2.16 & & 1.29 & 1.03 to 1.62 & & \\
\hline Per-allele & & & & & 1.21 & 1.01 to 1.45 & 0.039 & 1.09 & 0.99 to 1.21 & 0.08 & 0.35 \\
\hline \multicolumn{12}{|c|}{ LSP1 rs3817198 } \\
\hline$\pi$ & $1,075(46.1)$ & $142(44.4)$ & $\begin{array}{c}429 \\
(42.0)\end{array}$ & $718(42.7)$ & 1.00 & & & 1.00 & & & \\
\hline TC & $1,005(43.1)$ & $146(45.6)$ & $\begin{array}{c}466 \\
(45.6)\end{array}$ & $759(45.2)$ & 1.08 & 0.86 to 1.36 & & 1.14 & 1.01 to 1.29 & & \\
\hline CC & $252(10.8)$ & $32(10.0)$ & $\begin{array}{c}127 \\
(12.4)\end{array}$ & $203(12.1)$ & 1.02 & 0.68 to 1.51 & & 1.39 & 1.14 to 1.70 & & \\
\hline Per-allele & & & & & 1.03 & 0.87 to 1.22 & 0.70 & 1.17 & 1.07 to 1.28 & $5.5 \times 10^{-4}$ & 0.20 \\
\hline \multicolumn{12}{|c|}{$2 q 35$ rs13387042 } \\
\hline GG & $571(25.3)$ & $71(23.0)$ & $\begin{array}{c}216 \\
(22.0)\end{array}$ & $382(23.1)$ & 1.00 & & & 1.00 & & & \\
\hline GA & $1,080(47.8)$ & $156(50.5)$ & $\begin{array}{c}500 \\
(50.8)\end{array}$ & $809(48.8)$ & 1.12 & 0.85 to 1.47 & & 1.18 & 1.01 to 1.36 & & \\
\hline AA & $608(26.9)$ & $82(26.5)$ & $\begin{array}{c}268 \\
(27.2)\end{array}$ & $466(28.1)$ & 1.06 & 0.78 to 1.45 & & 1.13 & 0.95 to 1.34 & & \\
\hline Per-allele & & & & & 1.03 & 0.87 to 1.19 & 0.71 & 1.06 & 0.97 to 1.15 & 0.20 & 0.75 \\
\hline \multicolumn{12}{|c|}{$8 q 24$ rs13281615 } \\
\hline AA & $794(34.1)$ & 99 (31.6) & $\begin{array}{c}317 \\
(31.7)\end{array}$ & $524(31.3)$ & 1.00 & & & 1.00 & & & \\
\hline$A G$ & 1,156 (49.6) & $165(52.7)$ & $\begin{array}{c}511 \\
(51.1)\end{array}$ & 837 (49.9) & 1.08 & 0.85 to 1.38 & & 1.05 & 0.92 to 1.21 & & \\
\hline GG & $382(16.4)$ & $49(15.7)$ & $\begin{array}{c}172 \\
(17.2)\end{array}$ & $315(18.8)$ & 1.05 & 0.75 to 1.46 & & 1.13 & 0.94 to 1.35 & & \\
\hline Per-allele & & & & & 1.04 & 0.89 to 1.21 & 0.66 & 1.06 & 0.97 to 1.16 & 0.19 & 0.80 \\
\hline \multicolumn{12}{|c|}{ SLC4A7/NEK10 rs4973768 } \\
\hline $\mathrm{CC}$ & $669(26.5)$ & $82(24.9)$ & $\begin{array}{c}251 \\
(22.6)\end{array}$ & $401(23.5)$ & 1.00 & & & 1.00 & & & \\
\hline CT & $1,241(49.1)$ & $164(49.9)$ & $\begin{array}{c}546 \\
(49.4)\end{array}$ & $829(48.7)$ & 1.05 & 0.81 to 1.36 & & 1.14 & 0.99 to 1.31 & & \\
\hline$\pi$ & $618(24.5)$ & $83(25.2)$ & $\begin{array}{c}311 \\
(28.0)\end{array}$ & $474(27.8)$ & 1.04 & 0.77 to 1.41 & & 1.27 & 1.08 to 1.50 & & \\
\hline Per-allele & & & & & 1.02 & 0.88 to 1.19 & 0.78 & 1.13 & 1.04 to 1.22 & 0.0043 & 0.25 \\
\hline
\end{tabular}


Table 3 Genotype and per-allele hazard ratio estimates by estrogen receptor status for BRCA2 mutation carriers (Continued)

\begin{tabular}{|c|c|c|c|c|c|c|c|c|c|c|c|}
\hline \multicolumn{12}{|c|}{ STXBP4/COX11 rs6504950 } \\
\hline GG & $1,420(55.6)$ & $171(51.0)$ & $\begin{array}{l}601 \\
(53.1)\end{array}$ & $896(52.5)$ & 1.00 & & & 1.00 & & & \\
\hline GA & $951(37.2)$ & $145(43.3)$ & $\begin{array}{c}444 \\
(39.3)\end{array}$ & $684(40.1)$ & 1.27 & 1.03 to 1.58 & & 1.09 & 0.97 to 1.23 & & \\
\hline AA & $184(7.2)$ & $19(5.7)$ & $86(7.6)$ & $127(7.4)$ & 0.84 & 0.54 to 1.30 & & 1.08 & 0.87 to 1.34 & & \\
\hline Per-allele & & & & & 1.07 & 0.92 to 1.25 & 0.36 & 1.06 & 0.97 to 1.16 & 0.19 & 0.91 \\
\hline \multicolumn{12}{|c|}{$5 p 12$ rs10941679 } \\
\hline AA & $1,372(58.6)$ & $176(54.8)$ & $\begin{array}{c}584 \\
(54.8)\end{array}$ & $924(56.3)$ & 1.00 & & & 1.00 & & & \\
\hline AG & $824(35.2)$ & $122(38.0)$ & $\begin{array}{c}425 \\
(39.9)\end{array}$ & $622(37.9)$ & 1.08 & 0.86 to 1.37 & & 1.15 & 1.01 to 1.30 & & \\
\hline GG & $146(6.2)$ & $23(7.2)$ & $57(5.4)$ & $94(5.7)$ & 1.25 & 0.82 to 1.91 & & 0.94 & 0.73 to 1.22 & & \\
\hline Per-allele & & & & & 1.10 & 0.92 to 1.31 & 0.28 & 1.06 & 0.96 to 1.17 & 0.23 & 0.70 \\
\hline \multicolumn{12}{|c|}{$6 q 25.1-r s 2046210$} \\
\hline CC & $985(39.8)$ & $121(39.2)$ & $\begin{array}{c}466 \\
(42.1)\end{array}$ & $634(37.7)$ & 1.00 & & & 1.00 & & & \\
\hline $\mathrm{TC}$ & $1,165(47.1)$ & $132(42.7)$ & $\begin{array}{c}499 \\
(45.1)\end{array}$ & $802(47.7)$ & 0.99 & 0.78 to 1.12 & & 0.96 & 0.85 to 1.08 & & \\
\hline$\pi$ & $324(13.1)$ & $56(18.1)$ & $\begin{array}{c}141 \\
(12.8)\end{array}$ & $247(14.7)$ & 1.47 & 1.08 to 2.01 & & 0.94 & 0.78 to 1.12 & & \\
\hline Per-allele & & & & & 1.17 & 0.99 to 1.38 & 0.059 & 0.97 & 0.89 to 1.05 & 0.41 & 0.045 \\
\hline \multicolumn{12}{|l|}{$\begin{array}{l}\text { 1p11.2- } \\
\text { rs11249433 }\end{array}$} \\
\hline$\pi$ & 895 (35.9) & 107 (33.6) & $\begin{array}{c}345 \\
(31.4)\end{array}$ & $599(34.7)$ & 1.00 & & & 1.00 & & & \\
\hline CT & $1,226(49.2)$ & $160(50.3)$ & $\begin{array}{l}553 \\
(50.3)\end{array}$ & $843(48.9)$ & 1.00 & 0.79 to 1.28 & & 1.08 & 0.96 to 1.23 & & \\
\hline CC & $371(14.9)$ & $51(16.0)$ & $\begin{array}{c}202 \\
(18.4)\end{array}$ & $282(16.4)$ & 1.00 & 0.73 to 1.40 & & 1.27 & 1.08 to 1.50 & & \\
\hline Per-allele & & & & & 1.00 & 0.86 to 1.17 & 0.98 & 1.12 & 1.03 to 1.22 & 0.0065 & 0.23 \\
\hline \multicolumn{12}{|c|}{$\begin{array}{c}R A D 51 L 1-\mathrm{rs} 999737 / \\
\mathrm{rs} 10483813\end{array}$} \\
\hline BRCA1 & $\mathrm{CC} / \mathrm{TT}$ & $\begin{array}{l}1,368 \\
(59.5)\end{array}$ & $\begin{array}{c}167 \\
(59.0)\end{array}$ & $589(61.4)$ & $\begin{array}{l}1,000 \\
(62.0)\end{array}$ & 1.00 & & & 1.00 & & \\
\hline TC/AT & 789 (34.3) & $104(36.8)$ & $\begin{array}{l}323 \\
(33.6)\end{array}$ & $534(33.1)$ & 1.06 & 0.84 to 1.35 & & 0.94 & 0.83 to 1.07 & & \\
\hline TT/AA & $141(6.1)$ & $12(4.2)$ & $48(5.0)$ & $80(4.9)$ & 0.74 & 0.42 to 1.32 & & 0.87 & 0.67 to 1.14 & & \\
\hline Per-allele & & & & & 0.97 & 0.80 to 1.17 & 0.73 & 0.94 & 0.85 to 1.03 & 0.20 & 0.77 \\
\hline
\end{tabular}

$P$-het, Heterogeneity $P$-value; ER-, estrogen receptor negative; ER+, estrogen receptor positive

BRCA2 mutation carriers. The analysis was made possible by the availability of a large, combined dataset with genotype and tumour pathology information in mutation carriers collated through the CIMBA consortium.

The majority of the SNPs examined demonstrated stronger associations with ER-positive breast cancer for both BRCA1 and BRCA2 mutation carriers (Figure 2). Only rs2046210 on 6q25.1 exhibited stronger evidence for ER-negative disease. Among BRCA1 mutation carriers, the most marked difference was for SNP rs2981582 in FGFR2, which was strongly associated with ER-positive breast cancer and exhibited no evidence of an association with ER-negative breast cancer $(P=6.5 \times$ $\left.10^{-6}\right)$. Previous analyses of this polymorphism in mutation carriers failed to find an association with the overall risk of breast cancer for BRCA1 mutation carriers, but found an association with risk for $B R C A 2$ mutation carriers [29,31]. Our results suggest that rs2981582 in FGFR2 also modifies ER-positive breast cancer risk for $B R C A 1$ mutation carriers to a similar relative extent as in $B R C A 2$ mutation carriers and ERpositive disease in the general population [27,32]. Similar patterns were observed for SNPs rs3803662 in TOX3/TNRC9 and rs4973768 in SLC4A7/NEK10 in which the associations were predominantly with ERpositive breast cancer for both $B R C A 1$ and $B R C A 2$ mutation carriers, in line with results from studies of breast cancer in the general population $[18,21,27]$. The 


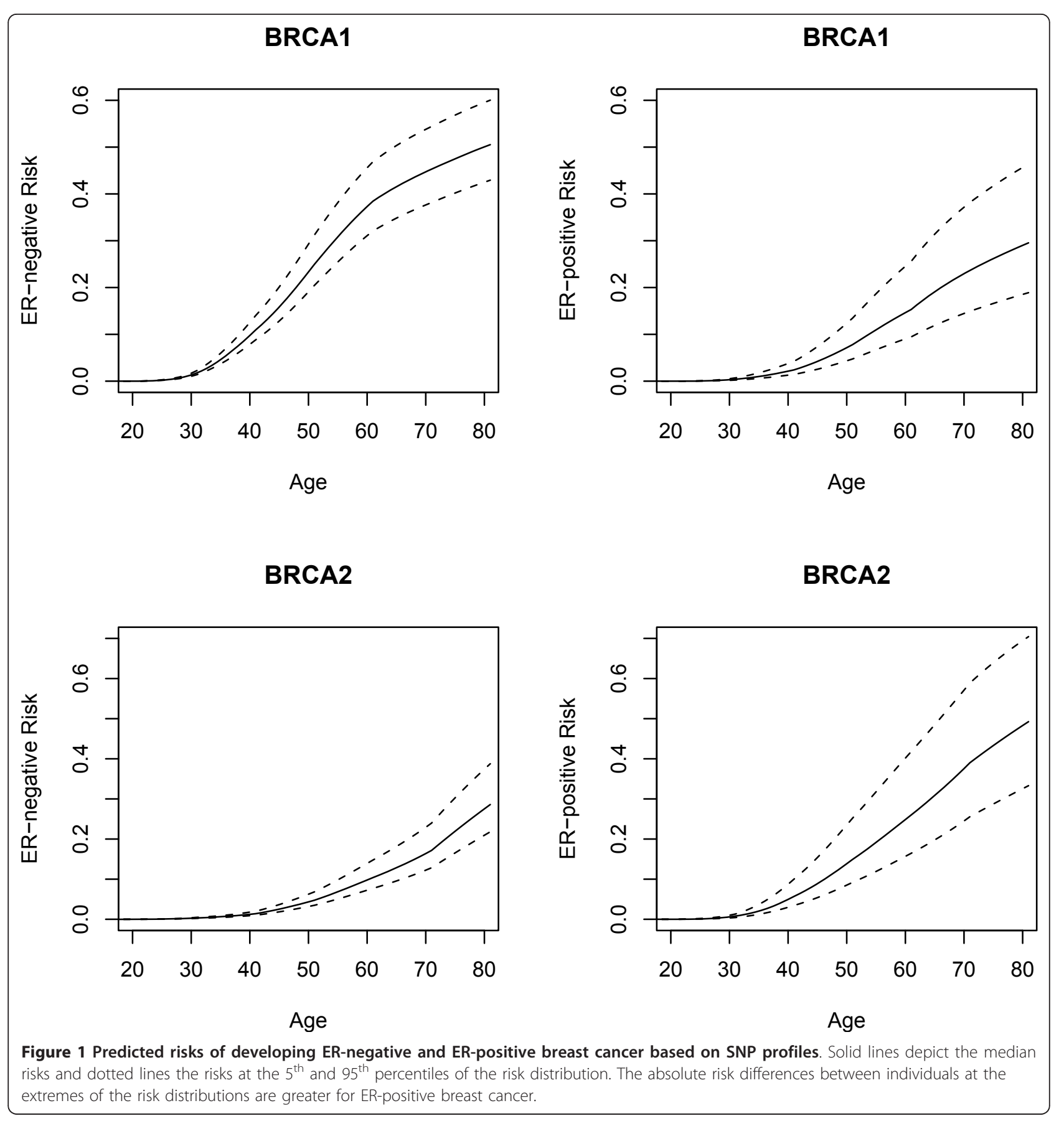

HR estimates for ER-positive breast cancer in $B R C A 1$ and $B R C A 2$ mutation carriers for these SNPs were very similar.

Among the 12 SNPs investigated in this report, SNP rs2046210 at 6q25.1 exhibited the strongest association with the risk of breast cancer for BRCA1 mutation carriers in previous analyses, and was not associated with risk for BRCA2 mutation carriers [28]. The current results suggest that this was mainly driven by an association with ER-negative breast cancer risk. This observation is again consistent with the effects seen in population-based studies, in which the relative risk is higher for ER-negative than ER-positive disease [42,43] (Alison Dunning, personal communication). There was some evidence that the $6 \mathrm{q} 25.1 \mathrm{SNP}$ is also associated with ER-negative disease cancer subtype in BRCA2 mutation carriers, although the estimates for ER-negative breast cancer in BRCA2 mutation carriers are 


\section{BRCA1}

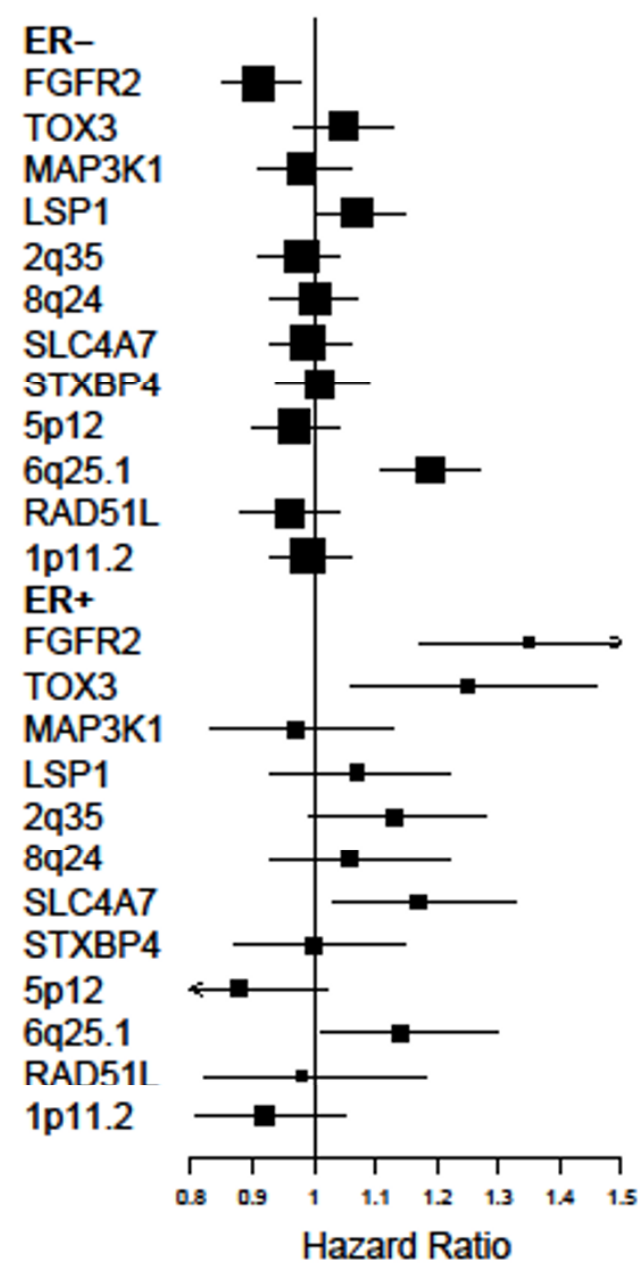

BRCA2

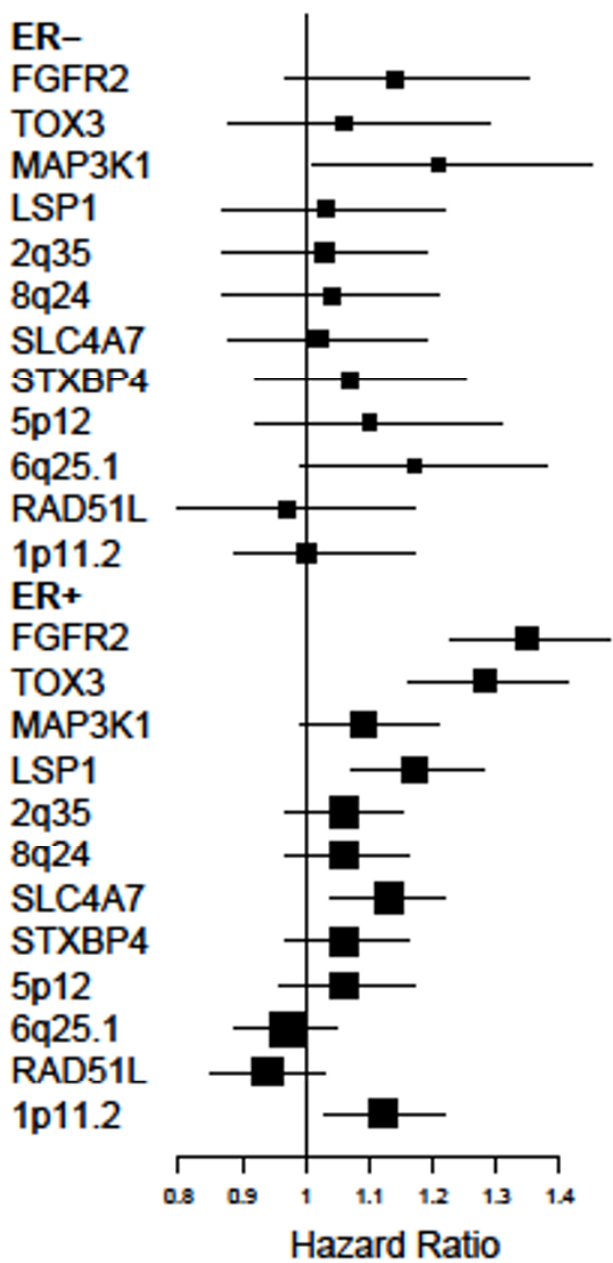

Figure 2 Summary of per-allele HR estimates for ER-positive and ER-negative breast cancer for mutation carriers. The patterns of perallele HR estimates (taken from Tables 2 and 3) suggest that the breast cancer subtype specific associations are similar between BRCA1 and BRCA2 mutation carriers.

imprecise due to the relatively small sample size. In addition to the 12 loci investigated in this report, a recently identified locus at $19 \mathrm{p} 13$ also appears to be predominantly associated with ER-negative breast cancer [44].

The patterns of association between the SNPs and PR tumour status were similar to those observed for ER, which is not surprising given that ER and PR expression are highly correlated. There were, however, two notable exceptions. The 2q35 SNP rs13387042 demonstrated significantly stronger associations with PR-positive than PR-negative breast cancer for both $B R C A 1$ and $B R C A 2$ mutation carriers $(P=0.034$ and $P=0.0086$, for PRpositive for $B R C A 1$ and $B R C A 2$ respectively), suggesting this SNP may be more relevant for $B R C A 1$ and $B R C A 2$ tumours expressing PR. However, a population-based study has found this SNP is also associated with PRnegative breast cancer [45]. Furthermore, the RAD51L1 locus was associated with PR-positive breast cancer for $B R C A 1$ mutation carriers and the magnitude of the association was similar to that observed in the general population [23] (A.B. Spurdle, personal communication).

Previous studies demonstrated that SNPs, which are associated with ER-positive breast cancer in the general population, tend to be associated with the breast cancer risk for BRCA2 mutation carriers and SNPs, which are associated with ER-negative breast cancer in the general population, tend to be associated with the breast cancer 
risk for $B R C A 1$ mutation carriers [27,31,44-46]. The current results demonstrate that despite lack of an association between a SNP and the overall breast cancer risk for $B R C A 1$ or BRCA2 mutation carriers, residual associations exist with specific disease subtypes. Figure 2 summarises the association patterns in $B R C A 1$ and $B R C A 2$ mutation carriers. The HR estimates for ERpositive and ER-negative breast cancer among BRCA1 mutation carriers appear to be different (intraclass correlation coefficient (ICC) approximately 0 ), as are the HR estimates for ER-positive and ER-negative breast cancer among BRCA2 mutation carriers $(\mathrm{ICC}=0.13$ ). On the other hand the HR estimates for ER-positive breast cancer among $B R C A 1$ and $B R C A 2$ mutation carriers appear to be more similar $(\mathrm{ICC}=0.65)$. There is, however, little correlation in the HR estimates for ERnegative breast cancer among BRCA1 and BRCA2 mutation carriers $(\mathrm{ICC}=0.05)$. However, SNP 6q25.1, which is mainly associated with ER-negative disease in BRCA1 mutation carriers, is estimated to confer similar HRs for ER-negative breast cancer for both BRCA1 and BRCA2 mutation carriers. These associations are mainly in the same direction and of similar magnitude to those observed with breast cancer in the general population stratified by ER expression status. Taken together, these findings are consistent with a model in which these SNPs and BRCA1 or BRCA2 mutations combine multiplicatively on the risk for ER-positive or ER-negative breast cancer [47]. Hence, the apparent differences in the strength of the SNP associations by BRCA1 and $B R C A 2$ mutation status can be explained once tumour subtype is taken into account.

The major strength of the current study is the large sample of $B R C A 1$ and $B R C A 2$ mutation carriers with SNP and tumour marker information. Despite the large sample size, ER and PR marker information was only available for approximately $30 \%$ of the mutation carriers that had been diagnosed with breast cancer. The sample sizes for tumour subtypes, while still large, were, therefore, much smaller than were available for analyses of breast cancer risk overall, particularly for ER-positive breast cancer in $B R C A 1$ carriers and ER-negative breast cancer in $B R C A 2$ carriers. However, by analysing the data using a retrospective cohort approach and analysing the associations with ER-positive and ER-negative disease simultaneously we were able to include all mutation carriers in the analysis, including affected individuals with missing ER status, thus maximizing the available information. Ongoing efforts by CIMBA aim to increase the proportion of mutation carriers diagnosed with breast cancer who also have available tumour pathology information. This will enable us to assess the associations with breast cancer subtypes with greater precision.
The majority of the mutation carriers in CIMBA are identified through clinical genetics centers and, therefore, the source of information or definition of tumour marker status could vary across studies. This heterogeneity in classification may attenuate some of the differences by tumour type. For example, most commonly, a cut-off of $10 \%$ of cells staining was taken to denote positivity for ER and PR by the centers without further information on intensity or proportion of positive tumour nuclei and this was used for all our analyses; however, in centers that use the Allred score, a value of $>2$ denoted positivity, which may reflect as few as $1 \%$ of cells staining. In fact, recent recommendations suggest that ER and PgR assays be considered positive, for therapeutic purposes, if there are at least $1 \%$ positive tumour nuclei [48], but these data were not available for the majority of carriers in our samples to enable reclassification. It has been shown, however, that ER is almost always diffusely positive or completely negative (that is, it shows a bimodal staining pattern) with few cases falling between these extremes [49]. Given the small number of tumours likely to fall into the 1 to $9 \%$ of cells staining category, the impact of changing the cutoff to $1 \%$ on our results would be limited. Furthermore, there was no evidence of variation in the distributions of ER or PR status across the studies separately for BRCA1 and BRCA2 tumours (Mavaddat N, Antoniou AC, personal communication, manuscript in preparation) and all analyses were stratified by country. Finally, the clear differences observed for some SNPs (most notably for FGFR2 rs2981582, where the association was limited to ER-positive disease) suggest that the effect of misclassification in tumour subtype on the SNP associations is likely to have been small.

BRCA1 and BRCA2 tumours have also been found to differ in terms of other tumour characteristics compared to breast cancers in the general population. For example, tumours in mutation carriers are more likely to be of higher grade in comparison to breast cancers in the general population. The distribution of grade has been found to vary between ER-positive and ER-negative tumours in both BRCA1 and BRCA2 mutation carriers (Mavaddat N, Antoniou AC, personal communication, manuscript in preparation). Although the number of carriers with information on grade, ER status and SNPs was too small to permit combined analysis, our results are unlikely to have been influenced after adjusting for tumour grade. Case-only analysis to test for differences in associations between the SNPs and tumour grade (using ordinal logistic regression) revealed no significant associations between any of the SNPs and grade for both BRCA1 and BRCA2 mutation carriers $(P>0.05$ for all tests, results not shown). 
The analysis was performed within a retrospective cohort approach, by extending the retrospective likelihood approach described previously [36] to model the simultaneous effects on different breast cancer subtypes defined by ER/PR. Under this approach the associations were estimated simultaneously for the tumour subtypes under investigation. This method depends on the assumption that ascertainment of mutation carriers does not depend on tumour subtypes. This is a reasonable assumption since more than $90 \%$ of mutation carriers in our sample were recruited prior to 2007, when it was uncommon to use tumour pathology in selecting individuals for BRCA1 and BRCA2 mutation screening. Furthermore, the results were virtually identical in a case only, logistic regression analysis for testing for differences in the associations with tumour subtypes which included only individuals with known tumour characteristics (results not shown).

The average risks of developing ER-positive and ERnegative breast cancer in both BRCA1 and BRCA2 mutation carriers are substantially higher compared to the general population [38]. Therefore, in combination, these SNPs lead to much bigger differences in the absolute risk of developing the disease subtypes between the extremes of the combined SNP genotype distributions [50]. Based on the SNP profiles investigated in this report, the absolute risk difference between mutation carriers at the top $5 \%$ of the risk distribution compared to the bottom $5 \%$ is much greater for ER-positive breast cancer than for ER-negative breast cancer for both BRCA1 and BRCA2 (Figure 1 ). Recent GWAS have identified several other common breast cancer susceptibility variants which have not been investigated in BRCA1 and BRCA2 mutation carriers yet [24,51]. Moreover, ongoing GWAS in $B R C A 1$ and BRCA2 mutation carriers [44,52] may also identify further modifiers of breast cancer risk for mutation carriers. It will be important to investigate the associations of these variants with different disease subtypes in BRCA1 and BRCA2 mutation carriers. Currently, it is unusual for the risks of different disease subtypes to be taken into account in the genetic counseling process. However, as more risk modifying variants are identified in the future, provided these have different associations with different disease subtypes in mutation carriers and confer relative risks which are greater (or smaller) than 1, having precise breast cancer subtype risks may be useful for the planning of the clinical management of both BRCA1 and BRCA2 mutation carriers. For example, knowing that a female BRCA1 mutation carrier was primarily at risk of ERpositive breast cancer based on her associated SNP profile (rather than ER-negative breast cancer, as is the case for the majority of cases) might potentially influence the choice of clinical management by screening, chemoprevention or prophylactic surgery.

\section{Conclusions}

In summary, in this report we investigated the associations of common breast cancer polymorphisms with ER and PR status. Our results indicate there are differential associations between these SNPs and the risk of developing ER-positive or ER-negative breast cancer in $B R C A 1$ and $B R C A 2$ mutation carriers that mirror similar differences seen in the general population. The findings add to our understanding of the biology of tumour development in mutation carriers and as more risk variants are identified in the future they may improve clinical management of these individuals.

\section{Additional material}

Additional file 1: Supplementary Tables. Supplementary Table 1: List of local ethics committees that approved studies. Supplementary Table 2: Methods and thresholds used to define the final marker variables. Supplementary Table 3: Per-allele hazard ratio estimates by progesterone receptor status for BRCA1 mutation carriers. Supplementary Table 4: Perallele hazard ratio estimates by progesterone receptor status for BRCA2 mutation carriers.

\section{Abbreviations}

CIMBA: Consortium of Investigators of Modifiers of BRCA1/2; ER: estrogen receptor; GWAS: genome-wide association studies; HR: hazard ratio; PR: progesterone receptor; SNPs: single nucleotide polymorphisms.

\section{Acknowledgements}

This work was supported by Cancer Research UK grants C12292/A11174 and C1287/A10118. The research leading to these results has received funding from the European Community's Seventh Framework Programme under grant agreement $n^{\circ} 223175$ (HEALTH-F2-2009-223175). ACA is a CR-UK Senior Cancer Research Fellow, DFE is CR-UK Principal Research Fellow. Study specific acknowledgments

Breast Cancer Family Registry (BCFR)

This work was supported by the National Cancer Institute, National Institutes of Health under RFA-CA-06-503 and through cooperative agreements with members of the Breast Cancer Family Registry (BCFR) and Principal Investigators, including Cancer Care Ontario (U01 CA69467), Columbia University (U01 CA69398), Fox Chase Cancer Center (U01 CA69631), Huntsman Cancer Institute (U01 CA69446), Cancer Prevention Institute of California (formerly the Northern California Cancer Center) (U01 CA69417), University of Melbourne (U01 CA69638), and Research Triangle Institute Informatics Support Center (RFP No. N02PC45022-46). Samples from the FCCC, $\mathrm{HCl}$, and CPIC were processed and distributed by the Coriell institute for Medical Research. The content of this manuscript does not necessarily reflect the views or policies of the National Cancer Institute or any of the collaborating centers in the BCFR, nor does mention of trade names, commercial products or organizations imply endorsement by the US Government or the BCFR.

The Baltic Familial Breast and Ovarian Cancer Consortium (BFBOCC Latvia and Lithuania)

Lithuania: This work is supported by the Research Council of Lithuania grant LIG-19/2010 to Ramunas Janavicius. Latvia: We acknowledge Genome

Database of Latvian Population, Latvian Biomedical Research and Study Center for providing data and DNA samples. This work is supported by Liepaja's municipal council to Laima Tihomirova (Latvian Biomedical Research and Study (entre).

Copenhagen Breast Cancer Study (CBCS) 
We thank the NEYE Foundation for financial support The Deutsches Krebsforschungszentrum (DKFZ) study The study was supported by the DKFZ.

The CONSIT TEAM is supported by grants from Associazione Italiana per la Ricerca sul Cancro (4017) and by funds from Italian citizens who allocated the $5 \times 1,000$ share of their tax payment in support of the Fondazione IRCCS Istituto Nazionale Tumouri, according to Italian laws (INT-Institutional strategic projects " $5 \times 1000$ ") to PP and grants from Fondazione Italiana per la Ricerca sul Cancro (Special Project "Hereditary tumours"), Ministero della Salute (Extraordinary National Cancer Program 2006 "Alleanza contro il Cancro", and "Progetto Tumouri Femminili") and Ministero dell'Universita' e Ricerca (RBLAO3-BETH) to PR. CONSIT TEAM acknowledges the contribution of Gaia Roversi, Carla B. Ripamonti, Marilena Morganti and Marco Pierotti of the of the Fondazione IRCCS Istituto Nazionale dei Tumouri, Milan, Italy; Monica Barile of the Istituto Europeo di Oncologia, Milan, Italy and Liliana Varesco of the Istituto Nazionale per la Ricerca sul Cancro, Genoa, Italy. Epidemiological study of BRCA1 and BRCA2 mutation carriers (EMBRACE) EMBRACE Collaborating Centers are: Coordinating Centre, Cambridge: Steve Ellis, Elena Fineberg, Radka Platte. North of Scotland Regional Genetics Service, Aberdeen: Zosia Miedzybrodzka. Northern Ireland Regional Genetics Service, Belfast: Patrick Morrison, Lisa Jeffers. West Midlands Regional Clinical Genetics Service, Birmingham: Trevor Cole, Kai-ren Ong, Jonathan Hoffman. South West Regional Genetics Service, Bristol: Margaret James. East Anglian Regional Genetics Service, Cambridge: Joan Paterson, Sarah Downing, Amy Taylor. Medical Genetics Services for Wales, Cardiff: T. Rogers,. St James's Hospital, Dublin \& National Centre for Medical Genetics, Dublin: M. John Kennedy, David Barton. South East of Scotland Regional Genetics Service, Edinburgh: Mary Porteous, Sarah Drummond. Peninsula Clinical Genetics Service, Exeter: Carole Brewer, Emma Kivuva, Anne Searle, Selina Goodman, Kathryn Hill. West of Scotland Regional Genetics Service, Glasgow: Victoria Murday, Nicola Bradshaw, Lesley Snadden, Mark Longmuir, Catherine Watt, Sarah Gibson, Eshika Haque, Ed Tobias, Alexis Duncan. South East Thames Regional Genetics Service, Guy's Hospital London: Chris Jacobs, Caroline Langman, Anna Whaite. North West Thames Regional Genetics Service, Harrow. Leicestershire Clinical Genetics Service, Leicester. Yorkshire Regional Genetics Service, Leeds: Carol Chu, Julie Miller. Cheshire and Merseyside Clinical Genetics Service, Liverpool: Ian Ellis. Manchester Regional Genetics Service, Manchester: Jane Taylor. North East Thames Regional Genetics Service, NE Thames, London: Alison Male, Cheryl Berlin. Nottingham Centre for Medical Genetics, Nottingham: Rebecca Collier. Northern Clinical Genetics Service, Newcastle: Fiona Douglas, Oonagh Claber, Irene Jobson. Oxford Regional Genetics Service, Oxford: Lisa Walker, Diane McLeod, Dorothy Halliday, Sarah Durell, Barbara Stayner. The Institute of Cancer Research and Royal Marsden NHS Foundation Trust: Susan Shanley, Nazneen Rahman, Richard Houlston, Elizabeth Bancroft, Lucia D'Mello, Elizabeth Page, Audrey Ardern-Jones, Kelly Kohut, Jennifer Wiggins, Elena Castro, Anita Mitra, Lisa Robertson. North Trent Clinical Genetics Service, Sheffield: Oliver Quarrell, Cathryn Bardsley. South West Thames Regional Genetics Service, London: Shirley Hodgson, Sheila Goff, Glen Brice, Lizzie Winchester, Charlotte Eddy, Vishakha Tripathi, Virginia Attard. Wessex Clinical Genetics Service, Princess Anne Hospital, Southampton: Anneke Lucassen, Gillian Crawford, Donna McBride, Sarah Smalley. EMBRACE is supported by Cancer Research UK Grants C1287/A10118 and C1287/A11990. D. Gareth Evans and Fiona Lalloo are supported by an NIHR grant to the Biomedical Research Centre, Manchester. The Investigators at The Institute of Cancer Research and The Royal Marsden NHS Foundation Trust are supported by an NIHR grant to the Biomedical Research Centre at The Institute of Cancer Research and The Royal Marsden NHS Foundation Trust. Ros Eeles, Elizabeth Bancroft and Lucia D'Mello are also supported by Cancer Research UK Grant C5047/A8385. Fox Chase Cancer Center Study (FCCC)

Fox Chase Cancer Center Biosample Repository: We acknowledge M. Pat Gilroy, Lesley Cruz, Diane Faison, Barbara Dettore, Mary Donovan, and Meghan Butler for their help collecting patient data and samples. University of Kansas Medical Center (KUMC):

A.K.G. was funded by U01CA69631, 5U01CA113916, and the Eileen Stein Jacoby Fund. The author acknowledges support from The University of Kansas Cancer Center and the Kansas Bioscience Authority Eminent Scholar Program. A.K.G. is the Chancellors Distinguished Chair in Biomedical Sciences endowed Professor.

Georgetown University
Work is supported by the Familial Cancer Registry $(\mathrm{Cl})$ and the Tissue Culture Shared Registry at Georgetown University ( $\mathrm{NIH/NCl}$ grant P30-CA051008), the Cancer Genetics Network (HHSN261200744000C) (CI), and Swing Fore the Cure $(\mathrm{Cl})$.

The German Consortium of Hereditary Breast and Ovarian Cancer (GC-HBOC) GC-HBOC is supported by a grant of the German Cancer Aid (grant 109076), the Centre of Molecular Medicine Cologne (CMMC).

Genetic Modifiers of cancer risk in BRCA1/2 mutation carriers (GEMO) study: Cancer Genetics Network "Groupe Génétique et Cancer", Fédération Nationale des Centres de Lutte Contre le Cancer, France The study was supported by the Ligue National Contre le Cancer; Association for International Cancer Research Grant (AICR-07-0454); and the Association "Le cancer du sein, parlons-en!" Award. We wish to thank all the GEMO collaborating groups for their contribution to this study. GEMO Collaborating Centers are: Coordinating Centres, Unité Mixte de Génétique Constitutionnelle des Cancers Fréquents, Centre Hospitalier Universitaire de Lyon/Centre Léon Bérard, et Equipe «Génétique du cancer du sein», Centre de Recherche en Cancérologie de Lyon: Laure Barjhoux, Carole Verny-Pierre, Sophie Giraud, and Service de Génétique Oncologique, Institut Curie, Paris: Marion Gauthier-Villars, Bruno Buecher, Claude Houdayer, Muriel Belotti, Carole Tirapo, Antoine de Pauw. Institut Gustave Roussy, Villejuif: Brigitte Bressac-de-Paillerets, Audrey Remenieras, Véronique Byrde, Olivier Caron, Gilbert Lenoir. Centre Jean Perrin, Clermont-Ferrand: Yves-Jean Bignon, Nancy Uhrhammer. Centre Léon Bérard, Lyon: Christine Lasset, Valérie Bonadona. Centre François Baclesse, Caen. Institut Paoli Calmettes, Marseille: Hagay Sobol, Violaine Bourdon, Tetsuro Noguchi, François Eisinger. Groupe Hospitalier Pitié-Salpétrière, Paris: Florence Coulet, Chrystelle Colas, Florent Soubrier. CHU de Arnaud-de-Villeneuve, Montpellier. Centre Oscar Lambret, Lille: Jean-Philippe Peyrat, Joëlle Fournier, Françoise Révillion, Philippe Vennin, Claude Adenis. Hôpital René Huguenin/Institut Curie, St Cloud: Etienne Rouleau, Rosette Lidereau, Liliane Demange, Catherine Nogues. Centre Paul Strauss, Strasbourg. Institut Bergonié, Bordeaux: Emmanuelle Barouk-Simonet, Françoise Bonnet, Virginie Bubien. Institut Claudius Regaud, Toulouse: Christine Toulas, Rosine Guimbaud, Laurence Gladieff, Viviane Feillel. CHU de Grenoble: Dominique Leroux, Hélène Dreyfus, Christine Rebischung, Magalie Peysselon. CHU de Dijon: Fanny Coron, Laurence Faivre. CHU de St-Etienne: Fabienne Prieur. Hôtel Dieu Centre Hospitalier, Chambéry: Sandra Fert Ferrer. Centre Antoine Lacassagne, Nice: Marc Frénay. CHU de Limoges: Laurence Vénat-Bouvet. CHU de Nantes: Capucine Delnatte. CHU Bretonneau, Tours. Creighton University, Omaha, USA: Henry T.Lynch, Carrie L.Snyder.

The Hereditary Breast and Ovarian Cancer Research Group Netherlands (HEBON)

HEBON Collaborating Centers: Coordinating center: Netherlands Cancer Institute, Amsterdam, NL: FBL Hogervorst, S Verhoef, M Verheus, LJ van 't Veer, FE van Leeuwen; Erasmus Medical Center, Rotterdam, NL: M Collée, AMW van den Ouweland, A Jager, MJ Hooning; Leiden University Medical Center, NL, Leiden: CJ van Asperen, JT Wijnen, MP Vreeswijk, RA Tollenaar, P Devilee; Radboud University Nijmegen Medical Center, Nijmegen, NL: MJ Ligtenberg, N Hoogerbrugge; University Medical Center Utrecht, Utrecht, NL: MG Ausems; Amsterdam Medical Center, NL: CM Aalfs; VU University Medical Center, Amsterdam, NL: JJP Gille, Q Waisfisz, HEJ Meijers-Heijboer; University Hospital Maastricht, Maastricht, NL: EB Gomez-Garcia, CE van Roozendaal, Marinus J Blok, B Caanen; University Medical Center Groningen University, NL: JC Oosterwijk, AH van der Hout, MJ Mourits; The Netherlands Foundation for the detection of hereditary tumours, Leiden, NL: HF Vasen. The HEBON study is supported by the Dutch Cancer Society grants NKI19981854, NKI2004-3088, NKI2007-3756 and the ZonMW grant 91109024. Helsinki Breast Cancer Study (HEBCS)

HEBCS acknowledge Drs. Kirsimari Aaltonen, Carl Blomqvist and Päivi Heikkilä and research nurse Irja Erkkilä for their help with the patient data and samples. The HEBCS study has been financially supported by the Helsinki University Central Hospital Research Fund, Academy of Finland (132473), the Finnish Cancer Society, and the Sigrid Juselius Foundation. Interdisciplinary Health Research International Team Breast Cancer Susceptibility (INHERIT BRCAs)

We would like to thank Martine Tranchant for skillful technical assistance. J.S. is Chairholder of the Canada Research Chair in Oncogenetics. This work was supported by the Canadian Institutes of Health Research for the "CIHR Team in Familial Risks of Breast Cancer" program and by the Canadian Breast Cancer Research Alliance-grant \#019511. 
ILUH

The ILUH group was supported by the Icelandic Association "Walking for Breast Cancer Research" and by the Landspitali University Hospital Research Fund.

Istituto Oncologico Veneto Hereditary Breast and Ovarian Cancer Study (IOVHBOCS)

This study was supported by "Ministero della Salute" ("Progetto Tumouri Femminili and grant numbers RFPS 2006-5-341353, ACC2/R6.9") Kathleen Cuningham Consortium for Research into Familial Breast Cancer (kConFab)

We wish to thank Heather Thorne, Eveline Niedermayr, all the kConFab research nurses and staff, the heads and staff of the Family Cancer Clinics, and the Clinical Follow Up Study (funded 2001-2009 by NHMRC and currently by the National Breast Cancer Foundation and Cancer Australia \#628333) for their contributions to this resource, and the many families who contribute to kConFab. kConFab is supported by grants from the National Breast Cancer Foundation, the National Health and Medical Research Council (NHMRC) and by the Queensland Cancer Fund, the Cancer Councils of New South Wales, Victoria, Tasmania and South Australia, and the Cancer Foundation of Western Australia. ABS and GCT are NHMRC Fellows. Mayo Clinic Study

The MAYO study was supported by NIH grants CA116167, CA128978, a Specialized Program of Research Excellence (SPORE) in Breast Cancer (CA116201), and awards from the Komen Foundation for the Cure and the Breast Cancer Research Foundation.

Memorial Sloan-Kettering Cancer Center (MSKCC)

The study is supported by grant from the Breast Cancer Research Foundation, Starr Cancer Consortium, Norman and Carol Stone Genetic Research Fund, The Robert and Kate Niehaus Clinical Genetics Initiative at MSKCC

National Cancer Institute study (NCl)

The research of Drs. PL Mai and MH Greene was supported by the Intramural Research Program of the US National Cancer Institute, and by support services contracts NO2-CP-11019-50 and N02-CP-65504 with Westat, Inc., Rockville, MD.

N.N. Petrov Institute of Oncology

This work has been supported by the Russian Federation for Basic Research (grants 10-04-92601, 10-04-92110, 11-04-00227), the Federal Agency for Science and Innovations (contract 02.740.11.0780), the Commission of the European Communities (grant PITN-GA-2009-238132) and through a Royal Society International Joint grant (JP090615).

Ontario Cancer Genetics Network (OCGN)

We wish to thank Mona Gill, Lucine Collins, Nalan Gokgoz, Teresa Selander, Nayana Weerasooriya and members of the Ontario Cancer Genetics Network for their contributions to the study.

The Ohio State University Comprehensive Cancer Center (OSU-CCG) This work was supported by the Ohio State University Comprehensive Cancer Center. We thank Kevin Sweet and Leigha Senter for accrual of study participants and data management. The Human Genetics Sample bank prepared DNA samples and the OSU Nucleic Acids Shared Resource assisted with genotyping.

Swedish BRCA1 and BRCA2 study (SWE-BRCA)

SWE-BRCA collaborators: Margareta Nordling, Annika Bergman and Zakaria Einbeigi, Gothenburg, Sahlgrenska University Hospital; Sigrun Liedgren, Linköping University Hospital; Åke Borg, Niklas Loman, Håkan Olsson, Ulf Kristoffersson, Helena Jernström, Katja Harbst, Lund University Hospital; Annika Lindblom, Annelie Liljegren, Gisela Barbany-Bustinza and Johanna Rantala, Stockholm, Karolinska University Hospital; Beatrice Melin, Henrik Grönberg, Eva-Lena Stattin and Monica Emanuelsson, Umeå University Hospital; Hans Ehrencrona, Richard Rosenquist and Niklas Dahl, Uppsala University Hospital.

University California San Francisco (UCSF)

The study received funding from the $\mathrm{NIH}, \mathrm{NCl}$ Bay Area Breast Cancer SPORE (P50 CA 058207) and the Avon Foundation. We acknowledge support from the UCSF Helen Diller Family Comprehensive Cancer Center

UK and Gilda Radner Familial Ovarian Cancer Registries (UKGRFOCR) UKFOCR was supported by a project grant from CRUK to Paul Pharoah. We thank Simon Gayther, Carole Pye, Patricia Harrington and Eva Wozniak for their contributions towards the UKFOCR. We'd like to acknowledge the Roswell Park Alliance Foundation for their continued support of the Gilda Radner Ovarian Family Cancer Registry. GRFOCR would like to acknowledge
Lara Sucheston (Department of Cancer Prevention and Control) and Kunle Odunsi (Departments Gynecologic Oncology and Immunology).

University of Pennsylvania (UPENN)

Work is supported by grants from the Breast Cancer Research Foundation (to KLN), MacDonald Family Foundation (SMD) and Komen Foundation (SMD)

\section{Author details}

'Department of Laboratory Medicine and Pathobiology, University of Toronto, Toronto, ON M5S 1A8, Canada; Department of Laboratory Medicine, and the Keenan Research Centre of the Li Ka Shing Knowledge Institute, St Michael's Hospital, 30 Bond Street, Toronto, ON M5B 1W8, Canada. ${ }^{2}$ Department of Laboratory Medicine and Pathology, Mayo Clinic, 200 First Street SW, Rochester, MN 55905, USA. ${ }^{3}$ Centre for Cancer Genetic Epidemiology, Department of Public Health and Primary Care, University of Cambridge, 2 Worts Causeway, Cambridge, CB1 8RN, UK. ${ }^{4}$ Department of Medicine, Abramson Cancer Center, Perelman School of Medicine at the University of Pennsylvania, 3400 Civic Center Boulevard, Philadelphia, PA 19104, USA. ${ }^{5}$ Faculty of Medicine, University of Southampton, University Hospital Southampton NHS Foundation Trust, Tremona Road, Southampton, SO16 6YD, UK. ${ }^{6}$ Department of Obstetrics and Gynecology, University of Helsinki and Helsinki University Central Hospital, Haartmaninkatu 8, 00290 Helsinki, Finland. 'Department of Preventive Medicine, Keck School of Medicine, University of Southern California, 2001 N Soto Street, Los Angeles, CA 90089-9237, USA. ${ }^{8}$ Department of Medicine, Memorial Sloan-Kettering Cancer Center and Weill Cornell Medical College, 1275 York Ave, New York, NY 10065, USA. ${ }^{9}$ National Cancer Institute, Division of Cancer Epidemiology and Genetics, Hormonal and Reproductive Epidemiology Branch, 6120 Executive Blvd., Rockville, MD 20852, USA. ${ }^{10}$ Queensland Institute of Medical Research, 300 Herston Rd, Herston, Brisbane, QLD 4006, Australia. ${ }^{11}$ Centre of Familial Breast and Ovarian Cancer, Department of Gynaecology and Obstetrics and Centre for Integrated Oncology $(\mathrm{ClO})$, University Hospital of Cologne, Kerpener Str. 62, Cologne, 50931, Germany. ${ }^{12}$ Unité Mixte de Génétique Constitutionnelle des Cancers Fréquents, Centre Hospitalier Universitaire de Lyon/Centre Léon Bérard, 28 rue Laënnec, Lyon 69373, France. ${ }^{13}$ INSERM U1052, CNRS UMR5286, Université Lyon 1, Cancer Research Center of Lyon, 28 rue Laënnec, Lyon 69373, France. ${ }^{14}$ Department of Molecular and Regenerative Medicine, Hematology, Oncology and Transfusion Medicine Center, Vilnius University Hospital Santariskiu Clinics, Santariskiu st 2, LT-08661 Vilnius and State Research Institute Innovative Medicine Center, Zygimantu st. 9, LT-01102 Vilnius, Lithuania. ${ }^{15}$ Center for Genomic Medicine, Rigshospitalet, Copenhagen University Hospital, Blegdamsvej 9, DK-2100 Copenhagen, Denmark. ${ }^{16}$ Department of Oncology, Rigshospitalet Bldg. 4262, Copenhagen University Hospital, Blegdamsvej 9, DK-2100 Copenhagen, Denmark. ${ }^{17}$ Human Genetics Group, Human Cancer Genetics Programme, Spanish National Cancer Research Centre, C/Melchor Fernández Almagro 3, Madrid, 28029, Spain and the Spanish Network on Rare Diseases (CIBERER). ${ }^{18}$ Institute of Biology and Molecular Genetics, Universidad de Valladolid (IBGM-UVA), C/Sanz y Forés, № 3, Valladolid, 47003, Spain. ${ }^{19}$ Instituto de investigación sanitaria de Aragón (IIS), Hospital clinico Universitario "Lozano Blesa", San Juan Bosco 15, Zaragoza, 50009, Spain. ${ }^{20}$ Molecular Diagnostics Laboratory, IRRP, National Center for Scientific Research Demokritos, Patriarchou Gregoriou E' \& Neapoleos Str, Ag. Paraskevi 15310, Athens, Greece. ${ }^{21}$ Human Genetics Group and Genotyping Unit, Human Cancer Genetics Programme, Spanish National Cancer Research Centre, C/Melchor Fernández Almagro 3, Madrid, 28029, Spain and the Spanish Network on Rare Diseases (CIBERER). ${ }^{22}$ Unit of Molecular Bases of Genetic Risk and Genetic Testing, Department of Preventive and Predictive Medicine, Fondazione IRCCS Istituto Nazionale Tumouri (INT), via Giacomo Venezian 1, 20133 Milan, Italy; IFOM, Fondazione Istituto FIRC di Oncologia Molecolare, via Adamello 16, 20139 Milan, Italy. ${ }^{23}$ Unit of Medical Genetics, Department of Preventive and Predictive Medicine, Fondazione IRCCS Istituto Nazionale Tumouri (INT), via Giacomo Venezian 1, Milan, 20133, Italy. ${ }^{24}$ Division of Cancer Prevention and Genetics, Istituto Europeo di Oncologia, via Ripamonti 435, Milan, 20141, Italy. ${ }^{25}$ Unit of Experimental Oncology 1, Centro di Riferimento Oncologico, IRCCS, Aviano (PN), Italy. ${ }^{26}$ Department of Genetics, Biology and Biochemlstry, University of Turin, Turin, Italy. ${ }^{27}$ Medical Genetics Unit, Department of Clinical Physiopathology, University of Florence, Firenze, Italy. ${ }^{28}$ Department of Molecular Medicine, "Sapienza" University of Rome, Rome, Italy. ${ }^{29}$ Division of Medical Oncology, Regina Elena Cancer Institute, Rome, Italy. ${ }^{30}$ Department of Experimental Oncology, 
Istituto Europeo di Oncologia. Milan, Italy; Consortium for Genomics Technology (Cogentech), Milan, Italy. ${ }^{31}$ Molecular Genetics of Breast Cancer, Deutsches Krebsforschungszentrum (DKFZ), Heidelberg, Germany. ${ }^{32}$ Department of Epidemiology, Netherlands Cancer Institute, Amsterdam, The Netherlands. ${ }^{33}$ Department of Clinical Genetics, VU Medical Center, Amsterdam, The Netherlands. ${ }^{34}$ Department of Human Genetics and Department of Clinical Genetics, Leiden University Medical Center, Leiden, The Netherlands. ${ }^{35}$ Department of Clinical Genetics and GROW, School for Oncology and Developmental Biology, MUMC, Maastricht, The Netherlands. ${ }^{36}$ Department of Human Genetics 849, Radboud University Nijmegen Medical Centre, P.O. BOX 9101, 6500 HB Nijmegen, The Netherlands. ${ }^{37}$ Department of Human Genetics 836, Radboud University Nijmegen Medical Centre, P.O. BOX 9101, 6500 HB Nijmegen, The Netherlands. ${ }^{38}$ Department of Medical Oncology, Family Cancer Clinic, Erasmus University Medical Center, Rotterdam, The Netherlands. ${ }^{39}$ Department of Surgical Oncology, Family Cancer Clinic, Erasmus University Medical Center, Rotterdam, The Netherlands. ${ }^{40}$ Department of Medical Genetics, University Medical Center Utrecht, The Netherlands. ${ }^{41}$ Department of Clinical Genetics, Academic Medical Center, Amsterdam, The Netherlands. ${ }^{42}$ Barts Cancer Institute, Queen Mary University of London, Centre for Tumour Biology, Charterhouse Square, London, UK. ${ }^{43}$ Genetic Medicine, Manchester Academic Health Sciences Centre, Central Manchester University Hospitals NHS Foundation Trust, Manchester, UK. ${ }^{44}$ Oncogenetics Team, The Institute of Cancer Research and Royal Marsden NHS Foundation Trust, UK. ${ }^{45} \mathrm{Clinical}$ Genetics, Guy's and St. Thomas' NHS Foundation Trust, London, UK. ${ }^{46}$ Yorkshire Regional Genetics Service, Leeds, UK. ${ }^{47}$ Ferguson-Smith Centre for Clinical Genetics, Yorkhill Hospitals, Glasgow, UK. ${ }^{48}$ Sheffield Clinical Genetics Service, Sheffield Children's Hospital, Sheffield, UK. ${ }^{49} \mathrm{Clinical}$ Genetics Department, St Michael's Hospital, Bristol, UK. ${ }^{50}$ North West Thames Regional Genetics Service, Kennedy-Galton Centre, Harrow, UK. ${ }^{51}$ North of Scotland Regional Genetics Service, NHS Grampian and University of Aberdeen, Foresterhill, Aberdeen, UK. ${ }^{52}$ Nottingham Clinical Genetics Service, Nottingham University Hospitals NHS Trust, UK. ${ }^{53}$ Cheshire and Merseyside Clinical Genetics Service, Liverpool Women's NHS Foundation Trust, Liverpool, UK. ${ }^{54}$ Leicestershire Clinical Genetics Service, University Hospitals of Leicester NHS Trust, UK. ${ }^{55}$ North East Thames Regional Genetics Service, Great Ormond Street Hospital for Children NHS Trust, London, UK. ${ }^{56} \mathrm{All}$ Wales Medical Genetics Service, Glan Clwyd Hospital, Rhyl, UK. ${ }^{57}$ All Wales Medical Genetics Services, Singleton Hospital, Swansea, UK. ${ }^{58}$ Department of Pathology and Laboratory Medicine, University of Kansas Medical Center, Kansas City, KS, USA. ${ }^{59}$ Institute for Medical Informatics, Statistics and Epidemiology, University of Leipzig, Leipzig, Germany. ${ }^{60}$ Department of Gynaecology and Obstetrics, Division of Tumour Genetics, Klinikum rechts der Isar, Technical University, Munich, Germany. ${ }^{61}$ Department of Gynaecology and Obstetrics, Ludwig-Maximillians University, Munich, Germany. ${ }^{62}$ Department of Gynaecology and Obstetrics, University Hospital of Schleswig-Holstein (UKSH), Campus Kiel, Christian-Albrechts University, Kiel, Germany. ${ }^{63}$ Department of Gynaecology and Obstetrics, University Hospital Düsseldorf, Heinrich-Heine University, Düsseldorf, Germany. ${ }^{64}$ Institute of Human Genetics, Department of Human Genetics, Heidelberg University Hospital, Heidelberg, Germany. ${ }^{65}$ Department of Gynaecology and Obstetrics, University Hospital, Ulm, Germany. ${ }^{66}$ Institute of Cell and Molecular Pathology, Hannover Medical School, Hannover, Germany. ${ }^{67}$ Department of Gynaecology and Obstetrics, University Hospital Carl Gustav Carus, Technical University, Dresden, Germany. ${ }^{68}$ Institute of Human Genetics, University of Münster, Münster, Germany. ${ }^{69}$ Institute of Human Genetics, Campus Virchov Klinikum, Charite Berlin, Germany. ${ }^{70}$ Centre of Familial Breast and Ovarian Cancer, Department of Medical Genetics, Institute of Human Genetics, University Würzburg, Germany. ${ }^{71}$ Institute of Human Genetics, University Regensburg, Germany. ${ }^{72}$ Institute of Human Genetics, University Leipzig, Germany. ${ }^{7 / 3}$ Institute of Human Genetics, University Hospital, Frankfurt a.M., Germany. ${ }^{74}$ Breakthrough Breast Cancer Research Centre, Institute of Cancer Research, UK. ${ }^{75}$ Service de Génétique Oncologique, Institut Curie, Paris, France. ${ }^{76}$ Genetic Unit, Avicenne Hospital, Assitance Publique-Hôpitaux de Paris, Paris, France; Sud-Francilien Hospital, Evry-Corbeil, France; University Hospital, Clermont-Ferrand, France. ${ }^{77}$ Centre François Baclesse, Caen, France. ${ }^{78}$ Unité d'Oncogénétique, CLCC Paul Strauss, Strasbourg, France. ${ }^{79}$ Service de Génétique, Centre Hospitalier Universitaire Bretonneau, Tours, France. ${ }^{80}$ Unité d'Oncogénétique, CHU Arnaud de Villeneuve, Montpellier, France. ${ }^{81}$ Service de Génétique Clinique Chromosomique et Moléculaire, Centre Hospitalier Universitaire de St
Etienne, St Etienne, France. ${ }^{82}$ Cancer Genetics Unit, INSERM U916, Institut Bergonié, Université de Bordeaux, Bordeaux, France. ${ }^{83}$ Unité INSERM U830, Institut Curie, Paris, France; Université Paris Descartes, Faculté de Médecine, Paris, France. ${ }^{84}$ Lombardi Comprehensive Cancer Center, Georgetown University, Washington DC, USA. ${ }^{85}$ Molecular Oncology Laboratory, Hospital Clinico San Carlos, Madrid, Spain. ${ }^{86}$ Department of Clinical Genetics, Helsinki University Central Hospital, Meilahdentie 2, 00290 Helsinki, Finland.

${ }^{87}$ Hereditary Cancer Program, Institut Català d'Oncologia, Hospital Duran i Reynals - Bellvitge Biomedical Research Institute (IDIBELL), L'Hospitalet de Llobregat, Barcelona, Spain. ${ }^{88}$ Department of Pathology, Landspitali University Hospital, Reykjavik, Iceland, Faculty of Medicine, University of Iceland, Reykjavik, Iceland. ${ }^{89}$ Cancer Genomics Laboratory, Centre Hospitalier Universitaire de Québec, 2705 Laurier Boulevard, T3-57, Quebec City, QC, Canada. ${ }^{90}$ Cancer Genomics Laboratory, Centre Hospitalier Universitaire de Québec, 2705 Laurier Boulevard, T3-57, Quebec City, QC, Canada; Canada Research Chair in Oncogenetics, Department of Molecular Medicine, Faculty of Medicine, Laval University, QC, Canada. ${ }^{91}$ Immunology and Molecular Oncology Unit, Istituto Oncologico Veneto IOV - IRCCS, Via Gattamelata 64, 35128 Padua, Italy. ${ }^{92}$ Department of Oncology and Surgical Sciences, University of Padua and Istituto Oncologico Veneto IOV - IRCCS, Via Gattamelata 64, 35128 Padua, Italy. ${ }^{93}$ Peter MacCallum Cancer Centre, Melbourne, VIC 3052, Australia. ${ }^{4}$ Department of Anatomical Pathology, Prince of Wales Hospital, Randwick, NSW 2031, Australia. ${ }^{95}$ Abramson Cancer Center and University of Pennsylvania Perelman School of Medicine, Philadelphia, PA, USA. ${ }^{96}$ University of Chicago, Chicago, IL, USA. ${ }^{97}$ City of Hope Comprehensive Cancer Center and Department of Population Sciences, Beckman Research Institute, City of Hope, Duarte, CA, USA. ${ }^{98}$ Departments of Medicine, and Preventive Medicine and Public Health, Creighton University, Omaha, NE, USA. ${ }^{99}$ Jonsson Comprehensive Cancer Center at the University of California, Los Angeles, CA, USA. ${ }^{100}$ Department of Internal Medicine and Harold C. Simmons Comprehensive Cancer Center, University of Texas, Southwestern Medical Center, Dallas, TX; USA: Department of Pediatrics, University of Texas Health Science Center at San Antonio, San Antonio, TX, USA. ${ }^{101}$ Department of Health Sciences Research, Mayo Clinic, Rochester, MN, USA. ${ }^{102}$ Department of Medical Genetics, Mayo Clinic, Rochester, MN, USA. ${ }^{103}$ University of Delaware, Newark, DE, USA. ${ }^{104}$ Epidemiology Research Program, American Cancer Society, Atlanta, GA, USA. ${ }^{105}$ Department of Obstetrics/Gynaecology and Comprehensive Cancer Center, Medical University of Vienna, Vienna, Austria. ${ }^{106} \mathrm{Clinical}$ Genetics Branch, Division of Cancer Epidemiology and Genetics, US National Cancer Institute, Rockville, MD, USA. ${ }^{107}$ Laboratory of Molecular Oncology, N.N. Petrov Institute of Oncology, St.-Petersburg, Russia. ${ }^{108}$ Department of Laboratory Medicine and Pathobiology, University of Toronto, Toronto, ON, Canada; Department of Laboratory Medicine, and the Keenan Research Centre of the Li Ka Shing Knowledge Institute, St Michael's Hospital, Toronto, ON, Canada. ${ }^{109}$ Samuel Lunenfeld Research Institute, Mount Sinai Hospital, Toronto; Department of Laboratory Medicine and Pathobiology, University of Toronto, ON, Canada. ${ }^{110}$ Cancer Care Ontario, ON, Canada. ${ }^{111}$ Departments of Molecular Virology, Immunology and Medical Genetics and Internal Medicine, The Ohio State University Comprehensive Cancer Center, Columbus, OH, USA. ${ }^{112}$ Clinical Genetics, Rigshospital, Copenhagen University, Copenhagen, Denmark. ${ }^{113}$ Clinical Genetics, Odense University Hospital, Odense, Denmark. ${ }^{114}$ Department of Clinical Genetics, Aarhus University Hospital, Aarhus, Denmark. ${ }^{115}$ Clinical Genetics, Vejle Hospital, Denmark. ${ }^{116}$ Section of Genetic Oncology, Dept. of Laboratory Medicine, University and University Hospital of Pisa, Pisa, Italy. ${ }^{17}$ Department of Clinical Genetics, Lund University Hospital, Lund, Sweden. ${ }^{118}$ Oncological Centre, Lund University Hospital, Lund, Sweden. ${ }^{119}$ Department of Oncology, Karolinska University Hospital, Stockholm, Sweden. ${ }^{120}$ Division of Clinical Genetics, Department of Clinical and Experimental Medicine, Linköping University, Linköping, Sweden. ${ }^{121}$ Department of Oncology, Sahlgrenska University Hospital, Gothenburg, Sweden. ${ }^{122}$ Department of Population Sciences, the Beckman Research Institute of the City of Hope, Duarte, CA, USA. ${ }^{123}$ UCSF Cancer Risk Program and Departments of Medicine and Epidemiology and Biostatistics, University of California San Francisco, San Francisco, CA, USA. ${ }^{124}$ Department of Oncology, University of Cambridge, Cambridge, UK. ${ }^{125}$ Department of Cancer Prevention and Control, Roswell Park Cancer Institute, Buffalo, NY, USA. ${ }^{126}$ Women's Cancer Program at the Samuel Oschin Comprehensive Cancer Institute, Cedars-Sinai Medical Center, Los Angeles, CA, USA. ${ }^{127}$ Department of Epidemiology, Cancer Prevention Institute of California, Fremont, CA, USA. ${ }^{128}$ Fox Chase Cancer Center, 
Philadelphia, PA, USA. ${ }^{129}$ Department of Oncological Sciences, Huntsman Cancer Institute, University of Utah, Salt Lake City, UT, USA. ${ }^{130}$ Genetic Epidemiology Laboratory, Department of Pathology, University of Melbourne, Melbourne, VIC, Australia. ${ }^{131}$ Centre for Molecular, Environmental, Genetic and Analytic Epidemiology, University of Melbourne, Melbourne, VIC, Australia. ${ }^{132}$ Department of Epidemiology, Columbia University, New York, NY, USA. ${ }^{133}$ Department of Cancer Biology, Dana-Farber Cancer Institute, Boston, MA, USA. ${ }^{134}$ Department of Dermatology, University of Utah School of Medicine, Salt Lake City, UT, USA. ${ }^{135}$ Samuel Lunenfeld Research Institute, Mount Sinai Hospital, 600 University Avenue, Toronto, ON, M5G 1X5, Canada; Cancer Care Ontario, Departments of Molecular Genetics and Laboratory Medicine and Pathobiology, University of Toronto, ON, Canada. ${ }^{136}$ Breast Cancer Family Registry. ${ }^{137}$ Cancer Genetics Network "Groupe Génétique et Cancer", Fédération Nationale des Centres de Lutte Contre le Cancer.

${ }^{138}$ Netherlands Cancer Institute, Amsterdam, The Netherlands. ${ }^{139}$ Ontario Cancer Genetics Network, Cancer Care Ontario, 620 University Avenue, Toronto, ON M5G 2L7, Canada. ${ }^{140}$ Karolinska Institute, Stockholm, Sweden.

\section{Authors' contributions}

AMM, ILA, ACA drafted the initial manuscript. ACA developed the analytical methods and performed the statistical analysis. AMM, ACA, ILA, FJC, DB, $S M D, D E, H N, S J R, M R, M S, A B S$ and BW are members of the CIMBA pathology working group and participated in the design of the study. LM and $D B$ are the CIMBA database managers. AL wrote computer programs for the analysis. SH and OMS reviewed, recoded and classified the BRCA1 and BRCA2 mutations in CIMBA. GCT initiated and coordinated CIMBA. DFE participated in the study design and advised on the statistical analysis. RJ, TVOH, FCNi, BE, AO, IMR, MD, JG, MP, JB, PP, SM, BP, DZ, EC, BB, AV, BP, LP, LO, AS, LB, PR, UH, MV, HEJMH, JW, EBGG, MRN, MK, CS, MMATL, RBVdL, TVO, $M R, D F, J L J, D G E, F L, R E, L I, J A, R D, J C, A D, H D, H G$, JE, CH, JB, LES, E MCC, $A M, S P, A G, R K S, K R, C E, A M, I R, N A, D N, C S, H D, D G, K K, S P A, R V M, I S, B F$, WH, DS, HG, VCM, FCFC, SM, ML, NBK, AH, PB, DM, JPF, IM, PP, IC, ML, CK, $M L, N S, D S L, C l, T C, M H, T H, K A, I B, C L, R B B, P S, M D, J S, M M, S T, E D A, S F, M Y$, TR, OO, JNW, HTL, PAG, GET, XW, ZF, VSP, NML, CS, KO, RS, MG, JB, NK, CFS, MKT, DGK, AFR, PLM, MHG, El, FPO, HO, GG, AET, AMG, MT, TAK, UBJ, ABS, MAC, MS, KH, AvW, BA, MSA, PK, YCD, SLN, MB, PDPP, KBM, KLN, BYK, JG, EMJ, MJD, SMB, MCS, JLH, MBT, WC, AFM and DG acquired phenotypic data and DNA samples or performed SNP genotyping. All authors read and approved the final manuscript.

\section{Competing interests}

The authors declare that they have no competing interests.

Received: 27 April 2011 Accepted: 2 November 2011

Published: 2 November 2011

\section{References}

1. Ford D, Easton DF, Bishop DT, Narod SA, Goldgar DE: Risks of cancer in BRCA1-mutation carriers. Breast Cancer Linkage Consortium. Lancet 1994, 343:692-695.

2. The Breast Cancer Linkage Consortium: Cancer risks in BRCA2 mutation carriers. J Natl Cancer Inst 1999, 91:1310-1316.

3. Thompson D, Easton DF: Cancer incidence in BRCA1 mutation carriers. Natl Cancer Inst 2002, 94:1358-1365.

4. Mavaddat N, Pharoah PD, Blows F, Driver KE, Provenzano E, Thompson D, Macinnis RJ, Shah M, Easton DF, Antoniou AC: Familial relative risks for breast cancer by pathological subtype: a population-based cohort study. Breast Cancer Res 2010, 12:R10.

5. Thompson D, Easton D: The genetic epidemiology of breast cancer genes. J Mammary Gland Biol Neoplasia 2004, 9:221-236.

6. Antoniou A, Pharoah PD, Narod S, Risch HA, Eyfjord JE, Hopper JL, Loman N, Olsson H, Johannsson O, Borg A, Pasini B, Radice P, Manoukian S, Eccles DM, Tang N, Olah E, Anton-Culver H, Warner E, Lubinski J, Gronwald J, Gorski B, Tulinius H, Thorlacius S, Eerola H, Nevanlinna H, Syrjäkoski K, Kallioniemi OP, Thompson D, Evans C, Peto J, et al: Average risks of breast and ovarian cancer associated with BRCA1 or BRCA2 mutations detected in case Series unselected for family history: a combined analysis of 22 studies. Am J Hum Genet 2003, 72:1117-1130.

7. Begg CB, Haile RW, Borg A, Malone KE, Concannon P, Thomas DC, Langholz B, Bernstein L, Olsen JH, Lynch CF, Anton-Culver H, Capanu M,
Liang X, Hummer AJ, Sima C, Bernstein JL: Variation of breast cancer risk among BRCA1/2 carriers. JAMA 2008, 299:194-201.

8. Ford D, Easton DF, Stratton M, Narod S, Goldgar D, Devilee P, Bishop DT, Weber B, Lenoir G, Chang-Claude J, Sobol H, Teare MD, Struewing J, Arason A, Scherneck S, Peto J, Rebbeck TR, Tonin P, Neuhausen S, Barkardottir R, Eyfjord J, Lynch H, Ponder BA, Gayther SA, ZeladaHedman $M$, et al: Genetic heterogeneity and penetrance analysis of the BRCA1 and BRCA2 genes in breast cancer families. The Breast Cancer Linkage Consortium. Am J Hum Genet 1998, 62:676-689.

9. Hopper JL, Southey MC, Dite GS, Jolley DJ, Giles GG, McCredie MR, Easton DF, Venter DJ: Population-based estimate of the average agespecific cumulative risk of breast cancer for a defined set of proteintruncating mutations in BRCA1 and BRCA2. Australian Breast Cancer Family Study. Cancer Epidemiol Biomarkers Prev 1999, 8:741-747.

10. Milne RL, Osorio A, Cajal TR, Vega A, Llort G, de la Hoya M, Diez O, Alonso MC, Lazaro C, Blanco I, Sánchez-de-Abajo A, Caldés T, Blanco A, Graña B, Durán M, Velasco E, Chirivella I, Cardeñosa EE, Tejada MI, Beristain E, Miramar MD, Calvo MT, Martínez E, Guillén C, Salazar R, San Román C, Antoniou AC, Urioste M, Benítez J: The average cumulative risks of breast and ovarian cancer for carriers of mutations in BRCA1 and BRCA2 attending genetic counseling units in Spain. Clin Cancer Res 2008, 14:2861-2869.

11. Simchoni S, Friedman E, Kaufman B, Gershoni-Baruch R, Orr-Urtreger A, Kedar-Barnes I, Shiri-Sverdlov R, Dagan E, Tsabari S, Shohat M, Catane R, King MC, Lahad A, Levy-Lahad E: Familial clustering of site-specific cancer risks associated with BRCA1 and BRCA2 mutations in the Ashkenazi Jewish population. Proc Natl Acad Sci USA 2006, 103:3770-3774.

12. Struewing JP, Hartge $P$, Wacholder S, Baker SM, Berlin M, McAdams M, Timmerman MM, Brody LC, Tucker MA: The risk of cancer associated with specific mutations of BRCA1 and BRCA2 among Ashkenazi Jews. N Engl J Med 1997, 336:1401-1408.

13. Sorlie T, Tibshirani R, Parker J, Hastie T, Marron JS, Nobel A, Deng S, Johnsen H, Pesich R, Geisler S, Demeter J, Perou CM, Lønning PE, Brown PO, Børresen-Dale AL, Botstein D: Repeated observation of breast tumour subtypes in independent gene expression data sets. Proc Natl Acad Sci USA 2003, 100:8418-8423.

14. van 't Veer $L$, Dai $H$, van de Vijver MJ, He YD, Hart AA, Mao M, Peterse $H L$, van der Kooy K, Marton MJ, Witteveen AT, Schreiber GJ, Kerkhoven RM, Roberts C, Linsley PS, Bernards R, Friend SH: Gene expression profiling predicts clinical outcome of breast cancer. Nature 2002, 415:530-536.

15. Lakhani SR, Jacquemier J, Sloane JP, Gusterson BA, Anderson TJ, van de Vijver MJ, Farid LM, Venter D, Antoniou A, Storfer-Isser A, Smyth E, Steel CM, Haites N, Scott RJ, Goldgar D, Neuhausen S, Daly PA, Ormiston W, McManus R, Scherneck S, Ponder BA, Ford D, Peto J, Stoppa-Lyonnet D, Bignon YJ, Struewing JP, Spurr NK, Bishop DT, Klijn JG, Devilee P, et al: Multifactorial analysis of differences between sporadic breast cancers and cancers involving BRCA1 and BRCA2 mutations. J Natl Cancer Inst 1998, 90:1138-1145.

16. Lakhani SR, Reis-Filho JS, Fulford L, Penault-Llorca F, van der Vijver M, Parry S, Bishop T, Benitez J, Rivas C, Bignon YJ, Chang-Claude J, Hamann U, Cornelisse CJ, Devilee P, Beckmann MW, Nestle-Krämling C, Daly PA, Haites N, Varley J, Lalloo F, Evans G, Maugard C, Meijers-Heijboer H, Klijn JG, Olah E, Gusterson BA, Pilotti S, Radice P, Scherneck S, Sobol H, et al: Prediction of BRCA1 status in patients with breast cancer using estrogen receptor and basal phenotype. Clin Cancer Res 2005, 11:5175-5180.

17. Bane AL, Beck JC, Bleiweiss I, Buys SS, Catalano E, Daly MB, Giles G, Godwin AK, Hibshoosh H, Hopper JL, John EM, Layfield L, Longacre T, Miron A, Senie R, Southey MC, West DW, Whittemore AS, Wu H, Andrulis IL, O'Malley FP: BRCA2 mutation-associated breast cancers exhibit a distinguishing phenotype based on morphology and molecular profiles from tissue microarrays. Am J Surg Pathol 2007, 31:121-128.

18. Ahmed S, Thomas G, Ghoussaini M, Healey CS, Humphreys MK, Platte R, Morrison J, Maranian M, Pooley KA, Luben R, Eccles D, Evans DG, Fletcher O, Johnson N, dos Santos Silva I, Peto J, Stratton MR, Rahman N, Jacobs K, Prentice R, Anderson GL, Rajkovic A, Curb JD, Ziegler RG, Berg CD, Buys SS, McCarty CA, Feigelson HS, Calle EE, Thun MJ, et al: Newly discovered breast cancer susceptibility loci on 3p24 and 17q23.2. Nat Genet 2009, 41:585-590.

19. Easton DF, Pooley KA, Dunning AM, Pharoah PD, Thompson D, Ballinger DG, Struewing JP, Morrison J, Field H, Luben R, Wareham N, Ahmed S, Healey CS, Bowman R, SEARCH collaborators, Meyer KB, 
Haiman CA, Kolonel LK, Henderson BE, Le Marchand L, Brennan P, Sangrajrang S, Gaborieau V, Odefrey F, Shen CY, Wu PE, Wang HC, Eccles D, Evans DG, Peto J, et al: Genome-wide association study identifies novel breast cancer susceptibility loci. Nature 2007, 447:1087-1093.

20. Hunter DJ, Kraft P, Jacobs KB, Cox DG, Yeager M, Hankinson SE, Wacholder S, Wang Z, Welch R, Hutchinson A, Wang J, Yu K, Chatterjee N, Orr N, Willett WC, Colditz GA, Ziegler RG, Berg CD, Buys SS, McCarty CA, Feigelson HS, Calle EE, Thun MJ, Hayes RB, Tucker M, Gerhard DS, Fraumeni JF Jr, Hoover RN, Thomas G, Chanock SJ: A genome-wide association study identifies alleles in FGFR2 associated with risk of sporadic postmenopausal breast cancer. Nat Genet 2007, 39:870-874

21. Stacey SN, Manolescu A, Sulem P, Rafnar T, Gudmundsson J, Gudjonsson SA, Masson G, Jakobsdottir M, Thorlacius S, Helgason A, Aben KK, Strobbe LJ, Albers-Akkers MT, Swinkels DW, Henderson BE, Kolonel LN, Le Marchand L, Millastre E, Andres R, Godino J, Garcia-Prats MD, Polo E, Tres A, Mouy M, Saemundsdottir J, Backman VM, Gudmundsson L, Kristjansson K, Bergthorsson JT, Kostic J, et al: Common variants on chromosomes $2 q 35$ and $16 q 12$ confer susceptibility to estrogen receptor-positive breast cancer. Nat Genet 2007, 39:865-869.

22. Stacey SN, Manolescu A, Sulem P, Thorlacius S, Gudjonsson SA, Jonsson GF, Jakobsdottir M, Bergthorsson JT, Gudmundsson J, Aben KK, Strobbe LJ, Swinkels DW, van Engelenburg KC, Henderson BE, Kolonel LN, Le Marchand L, Millastre E, Andres R, Saez B, Lambea J, Godino J, Polo E, Tres A, Picelli S, Rantala J, Margolin S, Jonsson T, Sigurdsson H, Jonsdottir T, Hrafnkelsson J, et al: Common variants on chromosome $5 \mathrm{p} 12$ confer susceptibility to estrogen receptor-positive breast cancer. Nat Genet 2008, 40:703-706.

23. Thomas G, Jacobs KB, Kraft P, Yeager M, Wacholder S, Cox DG, Hankinson SE, Hutchinson A, Wang Z, Yu K, Chatterjee N, Garcia-Closas M, Gonzalez-Bosquet J, Prokunina-Olsson L, Orr N, Willett WC, Colditz GA, Ziegler RG, Berg CD, Buys SS, McCarty CA, Feigelson HS, Calle EE, Thun MJ, Diver R, Prentice R, Jackson R, Kooperberg C, Chlebowski R, Lissowska J, et al: A multistage genome-wide association study in breast cancer identifies two new risk alleles at 1p11.2 and 14q24.1 (RAD51L1). Nat Genet 2009, 41:579-584

24. Turnbull C, Ahmed S, Morrison J, Pernet D, Renwick A, Maranian M, Seal S, Ghoussaini M, Hines S, Healey CS, Hughes D, Warren-Perry M, Tapper W, Eccles D, Evans DG, Breast Cancer Susceptibility Collaboration (UK), Hooning M, Schutte M, van den Ouweland A, Houlston R, Ross G, Langford C, Pharoah PD, Stratton MR, Dunning AM, Rahman N, Easton DF: Genome-wide association study identifies five new breast cancer susceptibility loci. Nat Genet 2010, 42:504-507.

25. Zeger SL, Liang KY, Albert PS: Models for longitudinal data: a generalized estimating equation approach. Biometrics 1988, 44:1049-1060.

26. Broeks A, Schmidt MK, Sherman ME, Couch FJ, Hopper JL, Dite GS, Apicella C, Smith LD, Hammet F, Southey MC, Van 't Veer $L$, de Groot R, Smit VT, Fasching PA, Beckmann MW, Jud S, Ekici AB, Hartmann A, Hein A, Schulz-Wendtland R, Burwinkel B, Marme F, Schneeweiss A, Sinn HP, Sohn C, Tchatchou S, Bojesen SE, Nordestgaard BG, Flyger H, Ørsted DD, et al: Low penetrance breast cancer susceptibility loci are associated with specific breast tumour subtypes: findings from the Breast Cancer Association Consortium. Hum Mol Genet 2011, 20:3289-3303.

27. Garcia-Closas M, Hall P, Nevanlinna H, Pooley K, Morrison J, Richesson DA, Bojesen SE, Nordestgaard BG, Axelsson CK, Arias Jl, Milne RL, Ribas G, González-Neira A, Benítez J, Zamora P, Brauch H, Justenhoven C, Hamann U, Ko YD, Bruening T, Haas S, Dörk T, Schürmann P, Hillemanns $P$, Bogdanova N, Bremer M, Karstens JH, Fagerholm R, Aaltonen K, Aittomäki K, et al: Heterogeneity of breast cancer associations with five susceptibility Loci by clinical and pathological characteristics. PLoS Genet 2008, 4: e1000054

28. Antoniou AC, Kartsonaki C, Sinilnikova O, Soucy P, McGuffog L, Healey S, Lee A, Peterlongo P, Manoukian S, Peissel B, Zaffaroni D, Cattaneo E, Barile M, Pensotti V, Pasini B, Dolcetti R, Giannini G, Putignano AL, Varesco L, Radice P, Mai PL, Greene MH, Andrulis IL, Glendon G, Ozcelik H, Thomassen M, Gerdes AM, Kruse TA, Birk Jensen U, Crüger DG, et al: Common alleles at $6 \mathrm{q} 25.1$ and $1 \mathrm{p} 11.2$ are associated with breast cancer risk for BRCA1 and BRCA2 mutation carriers. Hum Mol Genet 2011, 20:3304-3321.

29. Antoniou $A C$, Spurdle $A B$, Sinilnikova OM, Healey S, Pooley KA, Schmutzler RK, Versmold B, Engel C, Meindl A, Arnold N, Hofmann W, Sutter C, Niederacher D, Deissler H, Caldes T, Kämpjärvi K, Nevanlinna H,
Simard J, Beesley J, Chen X, Kathleen Cuningham Consortium for Research into Familial Breast Cancer, Neuhausen SL, Rebbeck TR, Wagner T, Lynch HT, Isaacs C, Weitzel J, Ganz PA, Daly MB, Tomlinson G, et al: Common breast cancer-predisposition alleles are associated with breast cancer risk in BRCA1 and BRCA2 mutation carriers. Am J Hum Genet 2008, 82:937-948.

30. Antoniou AC, Sinilnikova OM, McGuffog L, Healey S, Nevanlinna $H$, Heikkinen T, Simard J, Spurdle AB, Beesley J, Chen X, Kathleen Cuningham Foundation Consortium for Research into Familial Breast Cancer, Neuhausen SL, Ding YC, Couch FJ, Wang X, Fredericksen Z, Peterlongo P, Peissel B, Bonanni B, Viel A, Bernard L, Radice P, Szabo Cl, Foretova L, Zikan M, Claes K, Greene MH, Mai PL, Rennert G, Lejbkowicz F, et al: Common variants in LSP1, 2q35 and $8 \mathrm{q} 24$ and breast cancer risk for BRCA1 and BRCA2 mutation carriers. Hum Mol Genet 2009, 18:4442-4456.

31. Antoniou AC, Beesley J, McGuffog L, Sinilnikova OM, Healey S, Neuhausen SL, Ding YC, Rebbeck TR, Weitzel JN, Lynch HT, Isaacs C, Ganz PA, Tomlinson G, Olopade OI, Couch FJ, Wang X, Lindor NM, Pankratz VS, Radice P, Manoukian S, Peissel B, Zaffaroni D, Barile M, Viel A, Allavena A, Dall'Olio V, Peterlongo P, Szabo Cl, Zikan M, Claes K, et al: Common breast cancer susceptibility alleles and the risk of breast cancer for BRCA1 and BRCA2 mutation carriers: implications for risk prediction. Cancer Res 2010, 70:9742-9754.

32. Reeves GK, Travis RC, Green J, Bull D, Tipper S, Baker K, Beral V, Peto R, Bell J, Zelenika D, Lathrop M, Million Women Study Collaborators: Incidence of breast cancer and its subtypes in relation to individual and multiple low-penetrance genetic susceptibility loci. JAMA 2010, 304:426-434.

33. Chenevix-Trench G, Milne RL, Antoniou AC, Couch FJ, Easton DF, Goldgar DE: An international initiative to identify genetic modifiers of cancer risk in BRCA1 and BRCA2 mutation carriers: the Consortium of Investigators of Modifiers of BRCA1 and BRCA2 (CIMBA). Breast Cancer Res 2007, 9:104.

34. 2011 [http://www.srl.cam.ac.uk/consortia/cimba/eligibility/eligibility.html]

35. Antoniou AC, Goldgar DE, Andrieu N, Chang-Claude J, Brohet R, Rookus MA, Easton DF: A weighted cohort approach for analysing factors modifying disease risks in carriers of high-risk susceptibility genes. Genet Epidemiol 2005, 29:1-11.

36. Antoniou AC, Sinilnikova OM, Simard J, Leone M, Dumont M, Neuhausen SL, Struewing JP, Stoppa-Lyonnet D, Barjhoux L, Hughes DJ, Coupier I, Belotti M, Lasset C, Bonadona V, Bignon YJ, Genetic Modifiers of Cancer Risk in BRCA1/2 Mutation Carriers Study (GEMO), Rebbeck TR, Wagner T, Lynch HT, Domchek SM, Nathanson KL, Garber JE, Weitzel J, Narod SA, Tomlinson G, Olopade OI, Godwin A, Isaacs C, Jakubowska A, Lubinski J, et al: RAD51 135G-> C modifies breast cancer risk among BRCA2 mutation carriers: results from a combined analysis of 19 studies. Am J Hum Genet 2007, 81:1186-1200.

37. Antoniou AC, Pharoah PD, McMullan G, Day NE, Ponder BA, Easton D: Evidence for further breast cancer susceptibility genes in addition to BRCA1 and BRCA2 in a population-based study. Genet Epidemiol 2001, 21:1-18.

38. Mavaddat N, Rebbeck TR, Lakhani SR, Easton DF, Antoniou AC: Incorporating tumour pathology information into breast cancer risk prediction algorithms. Breast Cancer Res 2010, 12:R28.

39. Lange K, Weeks D, Boehnke M: Programs for Pedigree Analysis: MENDEL, FISHER, and dGENE. Genet Epidemiol 1988, 5:471-472.

40. Antoniou AC, Cunningham AP, Peto J, Evans DG, Lalloo F, Narod SA, Risch HA, Eyfjord JE, Hopper JL, Southey MC, Olsson H, Johannsson O, Borg A, Pasini B, Radice P, Manoukian S, Eccles DM, Tang N, Olah E, AntonCulver H, Warner E, Lubinski J, Gronwald J, Gorski B, Tryggvadottir L, Syrjakoski K, Kallioniemi OP, Eerola H, Nevanlinna H, Pharoah PD, et al: The BOADICEA model of genetic susceptibility to breast and ovarian cancers: updates and extensions. Br J Cancer 2008, 98:1457-1466.

41. Boos DD: On generalised score tests. American Statistician 1992, 46:327-333.

42. Stacey SN, Sulem P, Zanon C, Gudjonsson SA, Thorleifsson G, Helgason A, Jonasdottir A, Besenbacher S, Kostic JP, Fackenthal JD, Huo D, Adebamowo C, Ogundiran T, Olson JE, Fredericksen ZS, Wang X, Look MP Sieuwerts AM, Martens JW, Pajares I, Garcia-Prats MD, Ramon-Cajal JM, de Juan A, Panadero A, Ortega E, Aben KK, Vermeulen SH, Asadzadeh F, van Engelenburg KC, Margolin S, et al: Ancestry-shift refinement mapping of the C6orf97-ESR1 breast cancer susceptibility locus. PLoS Genet 2010, 6: e1001029 
43. Zheng W, Long J, Gao YT, Li C, Zheng Y, Xiang YB, Wen W, Levy S, Deming SL, Haines JL, Gu K, Fair AM, Cai Q, Lu W, Shu XO: Genome-wide association study identifies a new breast cancer susceptibility locus at 6q25.1. Nat Genet 2009, 41:324-328.

44. Antoniou AC, Wang X, Fredericksen ZS, McGuffog L, Tarrell R, Sinilnikova OM, Healey S, Morrison J, Kartsonaki C, Lesnick T, Ghoussaini M, Barrowdale D, EMBRACE, Peock S, Cook M, Oliver C, Frost D, Eccles D, Evans DG, Eeles R, Izatt L, Chu C, Douglas F, Paterson J, Stoppa-Lyonnet D, Houdayer C, Mazoyer S, Giraud S, Lasset C, Remenieras A, et al: A locus on $19 p 13$ modifies risk of breast cancer in BRCA1 mutation carriers and is associated with hormone receptor-negative breast cancer in the general population. Nat Genet 2010, 42:885-892.

45. Milne RL, Benitez J, Nevanlinna H, Heikkinen T, Aittomaki K, Blomqvist C, Arias Jl, Zamora MP, Burwinkel B, Bartram CR, Meindl A, Schmutzler RK, Cox A, Brock I, Elliott G, Reed MW, Southey MC, Smith L, Spurdle AB, Hopper JL, Couch FJ, Olson JE, Wang X, Fredericksen Z, Schürmann P, Bremer M, Hillemanns P, Dörk T, Devilee P, van Asperen CJ, et al: Risk of estrogen receptor-positive and -negative breast cancer and singlenucleotide polymorphism 2q35-rs13387042. J Natl Cancer Inst 2009, 101:1012-1018.

46. Mavaddat N, Antoniou AC, Easton DF, Garcia-Closas M: Genetic susceptibility to breast cancer. Mol Oncol 2010, 4:174-191.

47. Wacholder S, Han SS, Weinberg CR: Inference from a multiplicative model of joint genetic effects or ovarian cancer risk. J Natl Cancer Inst 2011, 103:82-83

48. Hammond ME, Hayes DF, Dowsett M, Allred DC, Hagerty KL, Badve S, Fitzgibbons $\mathrm{PL}$, Francis $\mathrm{G}$, Goldstein NS, Hayes M, Hicks DG, Lester S, Love $\mathrm{R}$, Mangu PB, McShane L, Miller K, Osborne CK, Paik S, Perlmutter J, Rhodes A, Sasano H, Schwartz JN, Sweep FC, Taube S, Torlakovic EE, Valenstein P Viale G, Visscher D, Wheeler T, Williams RB, et al: American Society of Clinical Oncology/College of American Pathologists guideline recommendations for immunohistochemical testing of estrogen and progesterone receptors in breast cancer (unabridged version). Arch Pathol Lab Med 2010, 134:e48-e72.

49. Collins LC, Botero ML, Schnitt SJ: Bimodal frequency distribution of estrogen receptor immunohistochemical staining results in breast cancer: an analysis of 825 cases. Am J Clin Pathol 2005, 123:16-20.

50. Milne RL, Antoniou AC: Genetic modifiers of cancer risk for BRCA1 and BRCA2 mutation carriers. Ann Oncol 2011, 22(Suppl 1):i11-i17.

51. Fletcher O, Johnson N, Orr N, Hosking FJ, Gibson LJ, Walker K, Zelenika D, Gut I, Heath S, Palles C, Coupland B, Broderick P, Schoemaker M, Jones M, Williamson J, Chilcott-Burns S, Tomczyk K, Simpson G, Jacobs KB, Chanock SJ, Hunter DJ, Tomlinson IP, Swerdlow A, Ashworth A, Ross G, dos Santos Silva I, Lathrop M, Houlston RS, Peto J: Novel breast cancer susceptibility locus at 9q31.2: results of a genome-wide association study. J Natl Cancer Inst 2011, 103:425-435.

52. Gaudet MM, Kirchhoff T, Green T, Vijai J, Korn JM, Guiducci C, Segre AV, McGee K, McGuffog L, Kartsonaki C, Morrison J, Healey S, Sinilnikova OM, Stoppa-Lyonnet D, Mazoyer S, Gauthier-Villars M, Sobol H, Longy M, Frenay M, GEMO Study Collaborators, Hogervorst FB, Rookus MA, Collée JM, Hoogerbrugge N, van Roozendaal KE, HEBON Study Collaborators, Piedmonte M, Rubinstein W, Nerenstone S, Van Le L, et al: Common genetic variants and modification of penetrance of BRCA2-associated breast cancer. PLoS Genet 2010, 6:e1001183.

doi:10.1186/bcr3052

Cite this article as: Mulligan et al.: Common breast cancer susceptibility alleles are associated with tumour subtypes in BRCA1 and BRCA2 mutation carriers: results from the Consortium of Investigators of Modifiers of BRCA1/2. Breast Cancer Research 2011 13:R110.

\section{Submit your next manuscript to BioMed Central and take full advantage of:}

- Convenient online submission

- Thorough peer review

- No space constraints or color figure charges

- Immediate publication on acceptance

- Inclusion in PubMed, CAS, Scopus and Google Scholar

- Research which is freely available for redistribution

Submit your manuscript at www.biomedcentral.com/submit
Ciomed Central 